\title{
Sensitivity of two-dimensional model predictions of ozone response to stratospheric aircraft: An update
}

\author{
David B. Considine \\ Applied Research Corporation, Landover, Maryland \\ Anne R. Douglass and Charles H. Jackman \\ NASA Goddard Space Flight Center, Greenbelt, Maryland
}

\begin{abstract}
The Goddard Space Flight Center two-dimensional model of stratospheric photochemistry and dynamics has been used to calculate the $\mathrm{O}_{3}$ response to stratospheric aircraft (high-speed civil transport (HSCT)) emissions. The sensitivity of the model $\mathrm{O}_{3}$ response was examined for systematic variations of five parameters and two reaction rates over a wide range, expanding on calculations by various modeling groups for the NASA High Speed Research Program and the World Meteorological Organization. In all, 448 model runs were required to test the effects of variations in the latitude, altitude, and magnitude of the aircraft emissions perturbation, the background chlorine levels, the background sulfate aerosol surface area densities, and the rates of two key reactions. No deviation from previous conclusions concerning the response of $\mathrm{O}_{3}$ to HSCTs was found in this more exhaustive exploration of parameter space. Maximum $\mathrm{O}_{3}$ depletions occur for high-altitude, low-latitude HSCT perturbations. Small increases in global total $\mathrm{O}_{3}$ can occur for low-altitude, high-latitude injections. Decreasing aerosol surface area densities and background chlorine levels increases the sensitivity of model $\mathrm{O}_{3}$ to the HSCT perturbations. The location of the aircraft emissions is the most important determinant of the model response. Response to the location of the HSCT emissions is not changed qualitatively by changes in background chlorine and aerosol loading. The response is also not very sensitive to changes in the rates of the reactions $\mathrm{NO}+\mathrm{HO}_{2} \rightarrow \mathrm{NO}_{2}+\mathrm{OH}$ and $\mathrm{HO}_{2}+\mathrm{O}_{3} \rightarrow \mathrm{OH}+2 \mathrm{O}_{2}$ over the limits of their respective uncertainties. Finally, levels of lower stratospheric $\mathrm{HO}_{x}$ generally decrease when the HSCT perturbation is included, even though there are large increases in $\mathrm{H}_{2} \mathrm{O}$ due to the perturbation.
\end{abstract}

\section{Introduction}

Stratospheric aircraft (high-speed civil transports (HSCTs)) are potential sources of stratospheric pollutants. A fleet of such aircraft would directly inject $\mathrm{NO}_{x}$ $\left(\mathrm{NO}_{x}=\mathrm{NO}+\mathrm{NO}_{2}\right)$ and $\mathrm{H}_{2} \mathrm{O}$ into the stratosphere as well as other compounds such as unburned hydrocarbons, $\mathrm{CO}_{2}, \mathrm{CO}, \mathrm{SO}_{2}$, and soot [Miake-Lye, 1992]. The $\mathrm{NO}_{x}$ and $\mathrm{H}_{2} \mathrm{O}$ injections from an economically viable fleet may be large enough to significantly affect stratospheric $\mathrm{O}_{3}$ levels [Douglass et al., 1992; Johnston et al., 1989]. The possible response of stratospheric $\mathrm{O}_{3}$ to a fleet of HSCTs has been studied extensively since the early 1970s because of these potentially large effects [Johnston, 1971; Johnston et al., 1989, and references therein].

Copyright 1995 by the American Geophysical Union.

Paper number 94JD02751.

0148-0227/95/94JD-02751\$05.00
Many recent studies have been conducted for the AESA (Atmospheric Effects of Stratospheric Aircraft) component of NASA's HSRP (High Speed Research Program) $[K o, 1992 ;$ Ko and Weisenstein, 1993; Ko and Douglass, 1993]. These studies have involved a number of modeling groups. Each group reported their model's prediction of $\mathrm{O}_{3}$ depletion to a few aircraft emission scenarios. The scenarios were carefully designed to be as realistic as possible in the magnitude and distribution of emissions, and correspond to different proposed fleet configurations. The studies then concentrated on comparing the predictions of the different models to these few realistic aircraft emission scenarios.

One reason to limit the studies to a small number of scenarios is that it is economical to do so. The standardization of the perturbations also aids in the intercomparison of the results of different models. In addition, if a model happens to be a completely accurate simulation of the real atmosphere, then the most realistic scenario will produce the best prediction of the atmospheric effects of stratospheric aircraft. 
Unfortunately, the validity of a model and its response to a perturbation is difficult to determine. As a result, it is hard to estimate the uncertainty of the model predictions. Intercomparison of the responses of different models to the same perturbation is one method. If there is a large intermodel difference then the confidence in the model predictions will be low. If there is very little variation then the confidence is higher, although the possibility does exist that all the models are incorrect in the same way. The scenariobased studies that have been conducted for the HSRP use this method to evaluate the uncertainty of the model predictions.

A second method of determining the uncertainty is by a systematic study of the response of a model to a wide range of perturbations and to a large variation in the input parameters of the model itself. If small changes in the perturbation produce large changes in model response, then the confidence in the model results will be reduced. Confidence will also decrease if the variation of a model parameter (such as a reaction rate or boundary condition) produces large changes in the model response. However, if large variations in the perturbation or the input parameters do not have a large effect on the model predictions, then the confidence that the model predictions are correct will be increased. In a recent evaluation of NASA's HSRP, the National Research Council's Panel on Atmospheric Effects of Stratospheric Aircraft suggested that more studies of this type be conducted [Graedel et al., 1994].

This paper details the results of a study of this second type, where the response of a model to systematic variations in both perturbation and input parameters is explored. Its primary goal is to evaluate the uncertainty of the model prediction of $\mathrm{O}_{3}$ response through parameter variation. A secondary goal is to examine the mechanisms that produce changes in model response when the HSCT perturbation or the model is changed. Other papers have dealt with the mechanisms in more detail. For instance, Considine et al. [1994], Tie et al. [1994], and Pitari et al. [1993] examined the effects of polar stratospheric clouds (PSCs) on HSCT perturbation predictions; Bekki and Pyle [1993] and Weisenstein et al. [1993] studied the impact of sulfate aerosols, and Jackman et al. [1991] looked at the effects of changes in the model residual circulation. This work is similar to that of Johnston et al. [1989]. It differs from that study by exclusively using the Goddard Space Flight Center (GSFC) two-dimensional model [Douglass et al., 1989; Jackman et al., 1990] instead of being based primarily on one-dimensional model results. In addition, the model incorporates heterogeneous reactions on a stratospheric sulfate aerosol (SSA) layer; the Johnston et al. study considered only gas phase reactions. Heterogeneous chemistry has since been found to be critically important to the chemistry of the lower stratosphere and in particular to its response to $\mathrm{NO}_{x}$ perturbations [Weisenstein et al., 1991]. Heterogeneous reactions on PSC surfaces are not considered.

Model response to variations in the altitude, latitude and magnitude of injection, background chlorine, and background aerosol surface area density are examined. In addition, the rates of two reactions, $\mathrm{NO}+\mathrm{HO}_{2} \rightarrow$ $\mathrm{NO}_{2}+\mathrm{OH}$ and $\mathrm{HO}_{2}+\mathrm{O}_{3} \rightarrow \mathrm{OH}+2 \mathrm{O}_{2}$, are varied over their uncertainty limits with fixed background chlorine and aerosol loading. These two reactions were chosen because the first is critical to interference between the $\mathrm{NO}_{x}$ and $\mathrm{HO}_{x}\left(\mathrm{HO}_{x}=\mathrm{H}+\mathrm{OH}+\mathrm{HO}_{2}\right)$ catalytic cycles that destroy $\mathrm{O}_{3}$, and the second has both a large uncertainty and an important role in determining the rate of $\mathrm{HO}_{x}$-induced $\mathrm{O}_{3}$ loss.

The organization of this paper is as follows: First, the GSFC two-dimensional model is described, including the different background aerosol and chlorine assumptions that are varied in this study. Second, the aircraft fleet perturbations are presented. Third, the response of global total ozone and column ozone to variations in fleet location and magnitude are examined. Following this, the response to changes in background chlorine and aerosol loading is presented. Finally, the changes induced by reaction rate variations are discussed.

\section{Model Description}

The GSFC two-dimensional stratospheric photochemistry model [Douglass et al., 1989; Jackman et al., 1990] has a $10^{\circ}$ latitudinal resolution, extending from $-85^{\circ}$ to $+85^{\circ}$. It has 30 levels equally spaced in log pressure, from the ground to $0.23 \mathrm{mbar}(\approx 60 \mathrm{~km}$ in approximately $2-\mathrm{km}$ increments.) The model time step is 1 day. A residual circulation is calculated using a 4-year zonal average of National Meteorological Center temperatures. Heating rates are taken from Dopplick et al. $[1974,1979]$ from the ground to $100 \mathrm{mbar}$, and from Rosenfield et al. [1987] from 100 mbar to the top of the model. Family chemistry approximations are used. The model calculates daytime average values of 55 species. Of these, 25 are transported. Bromine chemical reactions are included as well as the ClO dimer reactions important to the polar regions. The model $\mathrm{H}_{2} \mathrm{O}$ distribution consists of two components. First, a background $\mathrm{H}_{2} \mathrm{O}$ distribution derived from limb infrared monitor of the stratosphere (LIMS) data is included, as described by Jackman et al. [1990]. This distribution is changed monthly. Second, the $\mathrm{H}_{2} \mathrm{O}$ injected by the subsonic and supersonic aircraft fleets is a transported quantity with a production term due to the aircraft and loss due to rainout and photochemistry. The model constituent distributions compare favorably with those obtained from other two-dimensional models [Jackman et al., 1989; Prather and Remsberg, 1993].

Three heterogeneous reactions are included in the model formulation:

$$
\begin{aligned}
\mathrm{ClONO}_{2}+\mathrm{H}_{2} \mathrm{O} & \rightarrow \mathrm{HNO}_{3}+\mathrm{HOCl} \\
\mathrm{ClONO}_{2}+\mathrm{HCl} & \rightarrow \mathrm{HNO}_{3}+\mathrm{Cl}_{2} \\
\mathrm{~N}_{2} \mathrm{O}_{5}+\mathrm{H}_{2} \mathrm{O} & \rightarrow 2 \mathrm{HNO}_{3}
\end{aligned}
$$

These reactions occur in the atmosphere via interactions with aerosol particle surfaces. The surface interactions result in reaction rates far higher than would 
occur by a purely gas phase pathway [Hanson and Ravishankara, 1991].

Heterogeneous reactions are implemented in the model by specifying a sulfate aerosol surface area density $A$ at each model grid point. The surface area density is the total surface area available on the aerosol particles contained in a unit atmospheric volume. A "sticking" coefficient, $\gamma$, is also specified for each reaction. The sticking coefficient can be interpreted as the probability that a collision of a reacting molecule $\left(\mathrm{ClONO}_{2}\right.$ or $\left.\mathrm{N}_{2} \mathrm{O}_{5}\right)$ with the aerosol particle surface will result in a heterogeneous reaction. The total heterogeneous reaction rate also depends on the thermal velocity of the incident molecule, $v$. Thus the total reaction rate is given by:

$$
k_{j}=\gamma_{j} v_{l} \frac{A(\phi, z)}{4} .
$$

In this equation, $j=\{1,2,3\}$ denotes the number of the heterogeneous reaction listed above, and $l=$ $\left\{\mathrm{ClONO}_{2}, \mathrm{ClONO}_{2}, \mathrm{~N}_{2} \mathrm{O}_{5}\right\}$ indicates the molecule incident on the aerosol particle [Hofmann and Solomon, 1989]. The thermal velocity of the $\mathrm{ClONO}_{2}$ and $\mathrm{N}_{2} \mathrm{O}_{5}$ molecules are calculated using the formula $v_{l}=$ $\sqrt{\left(8 k^{\prime} T / \pi M_{l}\right)}$, where $k^{\prime}$ is Boltzmann's constant and $M_{l}$ is the molecular weight of the incident molecule in the reaction.

The sticking coefficient used for reaction (3) is a constant, $\gamma_{3}=0.1$. Reactions (1) and (2) are sensitive functions of the weight percent of $\mathrm{H}_{2} \mathrm{SO}_{4}$ characterizing the SSA [Hanson and Ravishankara, 1991]. Denoting this value by $W$, then

$$
\begin{aligned}
& \gamma_{1}=10^{(187-0074 W)} \\
& \gamma_{2}=0.1 \gamma_{1} .
\end{aligned}
$$

The weight percent of $\mathrm{H}_{2} \mathrm{SO}_{4}$ depends on the $\mathrm{H}_{2} \mathrm{O}$ partial pressure and on the zonal mean temperature. The relationship used is taken from data published by Steele and Hamill, [1981].

Four different assumptions for the SSA surface area density distribution are used: a no aerosol case and three others. The basic distribution $A$ is the same in each of these cases. This is multiplied by a prefactor $f$, where $f=1,2$, or 4 to give a low, medium, and high surface area density, respectively. The basic distribution is taken from World Meteorological Organization (WMO) [1992] and is based on measurements taken by the SAGE II satellite. This base distribution was also used in the HSRP scenario calculations. The $f=1$ case represents background sulfate conditions several years after any large injections of sulfur into the stratosphere. The high distribution $(f=4)$ corresponds to the median value of the SSA surface area densities over the last two decades [WMO, 1992]. Although this can be thought of as a volcanically perturbed sulfate distribution, the surface area densities are far smaller than can occur immediately after a major volcanic eruption.

This heterogeneous chemistry prescription is roughly comparable to the one used in recent scenario calculations conducted for the HSRP. There are some differences, however. In those runs, the thermal velocity
Table 1. Chlorine Boundary Conditions for the Low, Medium, and High Chlorine Conditions Used in This Study

\begin{tabular}{lccr}
\hline \multicolumn{1}{c}{ Species } & High Cl & Medium $\mathrm{Cl}_{y}$ & Low $\mathrm{Cl}_{y}$ \\
\hline CFC-11 & 260 & 124 & 50 \\
CFC-12 & 510 & 359 & 233 \\
CFC-113 & 70 & 49 & 31 \\
CFC-114 & 10 & 7.8 & 6.2 \\
CFC-115 & 8 & 7.2 & 6.6 \\
CCl & 100 & 34 & 12 \\
$\mathrm{HCFC}_{4} 22$ & 200 & 3.7 & 0.15 \\
$\mathrm{CH}_{3} \mathrm{CCl}$ & 150 & 0 & 0 \\
$\mathrm{Halon} 1211_{\mathrm{CH}_{3} \mathrm{Cl}}$ & 600 & 0.2 & 0 \\
\hline
\end{tabular}

Column 1 gives the constituent, and columns 2, 3, and 4 give the ground mixing ratio boundary condition for that constituent, in parts per trillion by volume (pptv). The high and medium cases are the same as was used in the third Atmospheric Effects of Stratospheric Aircraft report written for the High Speed Research Program [Ko and Douglass, 1999].

used was not calculated for each type of molecule as a function of temperature. Instead, it was taken to be a constant corresponding to a molecule with a molecular weight of 100 at a temperature of $204.4 \mathrm{~K}$ [ $\mathrm{Ko}$ and Weisenstein, 1993]. Reaction (2) was not included in the heterogeneous reaction set, and the sticking coefficient for reaction (1) was taken to be a function of the zonal mean temperature, $\gamma_{1}^{\prime}=0.006 \exp [-0.15(T-$ 200)]. Runs testing the model sensitivity to the same HSCT perturbation have been made using both prescriptions, with only small differences in the results.

The three sets of boundary conditions employed in this study correspond to low, medium, and high levels of background chlorine. Other source gas concentrations correspond to those expected for the 2015 atmosphere. The high and medium background chlorine conditions are those used in the scenario calculations, and contain 3.7 parts per billion by volume (ppbv) and $2.0 \mathrm{ppbv}$ chlorine, respectively. The low chlorine boundary conditions have a total chlorine content of $1.4 \mathrm{ppbv}$. The values of the different chlorine source gases for this boundary condition were obtained by assuming that all CFCs would be phased out in 1995, and concentrations of the gases would decay for 100 years according to the lifetimes given in chapter 8 of $W M O$ [1992]. The values of the different chlorine compounds used in the boundary conditions are given in Table 1.

\section{Aircraft Fleet Assumptions}

Emissions from a subsonic aircraft fleet are included in all of the simulations reported. The subsonic fleet is assumed to emit only $\mathrm{NO}_{x}$ and $\mathrm{H}_{2} \mathrm{O}$, as given by $K o$ [1992]. The magnitude of the aircraft emissions can be characterized by the total fuel consumed per year by the fleet, and an emission index (EI), which is the number of grams of pollutant released into the atmosphere per kilogram of fuel burned. The magnitude of the subsonic 
emission is $170 \times 10^{9} \mathrm{~kg} / \mathrm{yr}$, with an $\mathrm{EI}$ of 20.7 for $\mathrm{NO}_{\boldsymbol{x}}$ and 1230 for $\mathrm{H}_{2} \mathrm{O}$ emissions. The latitudinal distribution peaks in the northern midlatitudes and tapers off to the north and south.

The annual HSCT fleet fuel use is $70 \times 10^{9} \mathrm{~kg}$. Three different EIs for $\mathrm{NO}_{x}$ of 5,15 , or 45 are used to specify a low, medium, and high amount of $\mathrm{NO}_{x}$ injected by the HSCTs into the stratosphere. In all cases the EI for $\mathrm{H}_{2} \mathrm{O}$ injected by the stratospheric aircraft fleet is 1230 . The HSCT emissions are distributed over six adjoining model grid boxes, two in latitude and three in altitude. Half the material is injected at each of the two latitudes. Of the material injected at a single latitude, half is injected at the central grid box and the remaining half is divided between the upper and the lower grid boxes. The fleet emissions are therefore distributed over a region spanning $20^{\circ}$ latitude and about $6 \mathrm{~km}$ in altitude. This spatial distribution of emissions is designed to allow easy testing and interpretation of the model response to changes in the fleet location over a large range of altitudes and latitudes. It does not conform to expected latitudinal or vertical emission distributions based on current flight corridors.

The center of the distribution specified in the previous paragraph is varied over three model pressure levels to examine the sensitivity of the model response to the location of the aircraft emissions. These correspond approximately to 15,19 , and $23 \mathrm{~km}$ in altitude (120 mbar, $68 \mathrm{mbar}$, and $38.5 \mathrm{mbar}$ ). The distribution is also varied over three latitudes $\left(0^{\circ} \mathrm{N}, 30^{\circ} \mathrm{N}\right.$, and $\left.60^{\circ} \mathrm{N}\right)$, for a total of nine different fleet locations.

\section{Results}

The study consisted of the systematic variation of background chlorine over the low, medium, and high chlorine backgrounds and the aerosols over the zero, low, medium, and high cases for the 28 possible combinations of HSCT fleet location and magnitude (including one base run). This portion of the study required $12 \times 28$ or 336 runs. In addition, the two reaction rates were varied over their low and high uncertainty limits for the medium chlorine and aerosol case. This required an extra $4 \times 28$ or 112 runs, for a total of 448 model runs. The parameters varied in this study are shown in Table 2. All of the base runs included the subsonic emissions specified above, so the changes between the base and the perturbed runs are due to the HSCT emissions only. Representative results from these runs will be discussed and presented below.

The response of the model to the HSCT fleet can be quantified by the change in globally and annually averaged column $\mathrm{O}_{3}$ between the perturbed case and the base case:

$$
\Delta G \mathrm{O}_{3}^{\mathrm{HSCT}}=\frac{\mathrm{GO}_{3}^{\mathrm{HSCT}}-\mathrm{GO}_{3}^{\mathrm{BASE}}}{\mathrm{GO}_{3}^{\mathrm{BASE}}} .
$$

Here, $G \mathrm{O}_{3}^{\mathrm{BASE}}$ is the globally and annually averaged column ozone without the HSCT fleet, and $\mathrm{GO}_{3}^{\mathrm{HSCT}}$ is the same quantity for a run which is changed from the
Table 2. Parameters Varied in the Sensitivity Runs

\begin{tabular}{llll}
\hline \multicolumn{1}{c}{ Parameter } & \multicolumn{1}{c}{ Low } & Medium & \multicolumn{1}{c}{ High } \\
\hline Emission Index & $5 \mathrm{~g} / \mathrm{kg}$ & $15 \mathrm{~g} / \mathrm{kg}$ & $45 \mathrm{~g} / \mathrm{kg}$ \\
Latitude & $0^{\circ}$ & $30^{\circ} \mathrm{N}$ & $60^{\circ} \mathrm{N}$ \\
Altitude & $120 \mathrm{mbar}$ & $68 \mathrm{mbar}$ & $38.5 \mathrm{mbar}$ \\
Chlorine & $1.4 \mathrm{ppbv}$ & $2.0 \mathrm{ppbv}$ & $3.7 \mathrm{ppbv}$ \\
Aerosol & $\mathrm{A}$ & $2 \mathrm{~A}$ & $4 \mathrm{~A}$ \\
$k_{\mathrm{NO}, \mathrm{HO}_{2}}$ & $k-\sigma$ & $k$ & $k+\sigma$ \\
$\mathrm{k}_{\mathrm{HO}}, \mathrm{O}_{3}$ & $k-\sigma$ & $k$ & $k+\sigma$ \\
\hline
\end{tabular}

Runs were made for every possible combination of the first five parameters. In addition, a zero background aerosol case was included and runs were made for every combination of emission index, fleet location, and chlorine background. Runs made in which the final two parameters were varied used the medium values of background chlorine and aerosol loading. Runs were then made with every combination of fleet location and magnitude of emissions. The low and high uncertainty limits for each of these reactions was determined using values obtained from DeMore et al. [1992].

base only by the addition of the HSCT perturbation. In terms of $\Delta G \mathrm{O}_{3}^{\text {HSCT }}$, the runs obey the following general relationships: (1) $G \mathrm{O}_{3}^{\mathrm{HSCT}}$ decreases as the fleet altitude is increased (negative change in $\Delta G \mathrm{O}_{3}^{\mathrm{HSCT}}$ ). (2) $\mathrm{GO}_{3}^{\mathrm{HSCT}}$ increases as the fleet latitude is increased (positive change in $\Delta G \mathrm{O}_{3}^{\mathrm{HSCT}}$ ). (3) There is a positive change in $\Delta G \mathrm{O}_{3}^{\mathrm{HSCT}}$ for increased levels of background chlorine. (4) There is a positive change in $\Delta G \mathrm{O}_{3}^{\text {HSCT }}$ for increased levels of background aerosols.

Note that in cases 3 and 4 we are interested in the effect that changes in background chlorine or aerosol surface area density have on the model response to the HSCT perturbation. This should not be confused with the direct response of the model to changes in background chlorine or aerosols. There are significant variations in $G_{3}^{\mathrm{BASE}}$ from case to case.

The response of $\Delta G \mathrm{O}_{3}^{\mathrm{HSCT}}$ to increases in emission index is more complicated and depends on the fleet location as well as background amounts of chlorine and aerosols. When the fleet location is at high altitudes and low latitudes, increases in emissions will produce a strong negative response. However, in the low-altitude, high-latitude runs $\Delta G \mathrm{O}_{3}^{\mathrm{HSCT}}$ can increase with increasing aircraft emissions due to lower stratospheric $\mathrm{HO}_{x}-\mathrm{NO}_{x}$ interactions and $\mathrm{NO}_{x}$ participation in $\mathrm{CH}_{4}$ oxidation. These changes will be studied in more detail below.

\section{Effects of Changes in Fleet Location}

The basic behavior of $\Delta G \mathrm{O}_{3}^{\mathrm{HSCT}}$ can be seen in Figures $1 \mathrm{a}, 1 \mathrm{~b}$, and $1 \mathrm{c}$. Figure $1 \mathrm{a}$ shows the variation in $\Delta G \mathrm{O}_{3}^{\mathrm{HSCT}}$ as a function of emission index for the three pressure levels of injection. The injection latitude is $0^{\circ}$. Figures $1 \mathrm{~b}$ and $1 \mathrm{c}$ show the same results for the $30^{\circ}$ and $60^{\circ}$ injection latitudes, respectively. All of the figures are for the middle background chlorine and aerosol surface area densities.

Examination of these plots shows that the response of $\Delta G \mathrm{O}_{3}^{\mathrm{HSCT}}$ to increasing emission index is a sensi- 

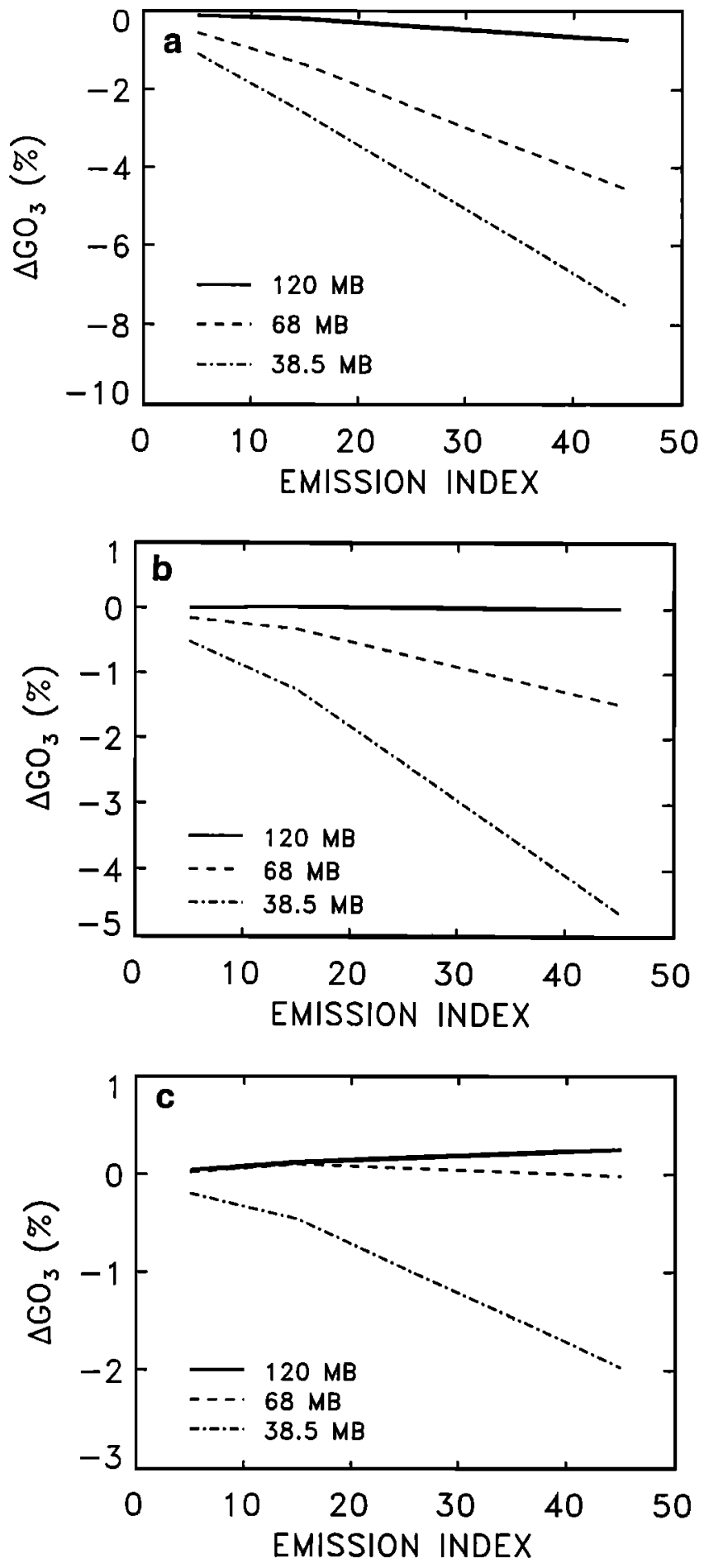

Figure 1. (a) Response of $\Delta G \mathrm{O}_{3}^{\mathrm{HSCT}}$ to emission index and fleet altitude for a fleet located at the equator. $\Delta G \mathrm{O}_{3}^{\mathrm{HSCT}}$ is the annually and latitudinally averaged column ozone change due to the HSCT emissions, in percent. The solid line shows the response for the lowaltitude fleet location at $120 \mathrm{mbar}(\approx 15 \mathrm{~km})$. Dashed line, middle-altitude fleet location of $68 \mathrm{mbar}(\approx 19$ $\mathrm{km})$. Dash-dot line, high-altitude fleet location of $\mathbf{3 8 . 5}$ mbar $(\approx 23 \mathrm{~km})$. (b) Same as Figure 1a, for the midlatitude fleet location of $30^{\circ}$. (c) Same as Figure 1a, for the high-latitude fleet location of $60^{\circ}$. All figures are for the middle background chlorine and aerosol surface area density distribution described in the text. tive function of fleet location, and in particular, fleet altitude. The largest depletion for these chlorine and aerosol amounts of about $-7.5 \%$ occurs for a fleet position of $0^{\circ}, 38.5 \mathrm{mbar}$, and $\mathrm{EI}=45$. At low altitudes and high latitudes, $\Delta G \mathrm{O}_{3}^{\mathrm{HSCT}}$ is positive and increases with increasing emission index, as shown in Figure 1c. Here, $\Delta G \mathrm{O}_{3}^{\text {HSCT }}$ is $+0.25 \%$ for the $60^{\circ}, 120 \mathrm{mbar}$, EI $=45$ case. The largest sensitivity to emission index occurs for high altitude fleet locations. Increasing the fleet latitude reduces the sensitivity of the model to changes in the emission index. At high altitudes and latitudes, there is an increase in the sensitivity of $\Delta G \mathrm{O}_{3}^{\mathrm{HSCT}}$ to emission index at higher emission rates. This is seen by the steeper slope between the EI $=15$ and the EI = 45 cases, as compared to the slope between the $\mathrm{EI}=5$ and the EI $=15$ cases in the Figure 1c 38.5-mbar plot. Finally, for low-altitude fleet emissions the model is relatively insensitive to increases in $\mathrm{NO}_{x}$ at all injection latitudes.

Changes in background chlorine and aerosol surface area density affect the behavior shown in Figure 1 quantitatively but not qualitatively. The effects will be discussed in more detail below.

The response of $\mathrm{O}_{3}$ to variations in the location and magnitude of the HSCT $\mathrm{NO}_{x}$ emissions depends on three factors: (1) the HSCT-induced increase in atmospheric $\mathrm{NO}_{y}$ loading (where $\mathrm{NO}_{y}$ is the sum of all odd nitrogen species: $\mathrm{NO}_{y}=\mathrm{N}+\mathrm{NO}+\mathrm{NO}_{2}+\mathrm{NO}_{3}+2 \mathrm{~N}_{2} \mathrm{O}_{5}+$ $\mathrm{HO}_{2} \mathrm{NO}_{2}+\mathrm{ClONO}_{2}+\mathrm{HNO}_{3}$ ); (2) the partitioning of the $\mathrm{NO}_{y}$ increase between active and inactive $\mathrm{NO}_{y}$; and (3) the spatial distribution of the increase. Table 3 shows how these factors combine to produce the $\mathrm{O}_{3}$ response to the HSCT fleet. The first three columns list the magnitude, latitude, and approximate altitude of the perturbation. Column 4 lists the annually averaged increase in the amount of atmospheric $\mathrm{NO}_{y}$, expressed in molecules of $\mathrm{NO}_{y}$. Column 5 shows the increase in $\mathrm{NO}_{x}$; column 6 gives the active/inactive $\mathrm{NO}_{y}$ ratio for the increase; column 7 gives the change in the number of $\mathrm{O}_{3}$ molecules; and column 8 gives the number of molecules of $\mathrm{O}_{3}$ lost per extra molecule of $\mathrm{NO}_{x}$ in the atmosphere. All of the above information is taken from runs with middle levels of background chlorine and aerosol loading.

Column 4 shows the variation of $\mathrm{NO}_{y}$ loading with altitude and latitude. $\mathrm{NO}_{y}$ loading increases by about a factor of 3 from the lowest to highest altitude and decreases by about a factor of 2 from the lowest to the highest latitude. For comparison the annual stratospheric source of $\mathrm{NO}_{y}$ from $\mathrm{N}_{2} \mathrm{O}$ oxidation is $2.6 \times 10^{34}$ molecules/yr. The increases in atmospheric $\mathrm{NO}_{y}$ shown in Table 3 are thus up to several times current inputs [Douglass et al., 1992].

Column 5 shows the $\mathrm{NO}_{x}$ variation. The same factor of 3 change with increased altitude occurs. However, $\mathrm{NO}_{x}$ loading decreases more strongly as a function of latitude of injection, with over a factor of 3 decrease from the lowest to highest latitudes. Thus the $\mathrm{NO}_{x}$ loading depends both on the $\mathrm{NO}_{y}$ increase and the partitioning. At higher latitudes, more of the HSCT per- 
Table 3. Changes in the Atmospheric Loading of $\mathrm{NO}_{x}, \mathrm{NO}_{y}, \mathrm{O}_{3}$, Ratio of Increase in Active Chlorine to Increase in Inactive Chlorine, and Sensitivity of $\mathrm{O}_{3}$ to Increases in $\mathrm{NO}_{x}$

\begin{tabular}{|c|c|c|c|c|c|c|c|}
\hline EI & Latitude & Altitude & $\Delta \mathrm{NO}_{y}(34)$ & $\Delta \mathrm{NO}_{x}(34)$ & Active/Inactive & $\Delta \mathrm{O}_{3}(34)$ & $\Delta \mathrm{O}_{3} / \Delta \mathrm{NO}_{\mathrm{x}}$ \\
\hline 5 & $0^{\circ}$ & 120.0 & 0.429 & 0.102 & 0.314 & -4.46 & -43.6 \\
\hline 5 & $0^{\circ}$ & 68.0 & 1.015 & 0.221 & 0.279 & -23.7 & -107.1 \\
\hline 5 & $0^{\circ}$ & 38.5 & 1.204 & 0.281 & 0.305 & -45.1 & -160.6 \\
\hline 5 & $30^{\circ}$ & 120.0 & 0.274 & 0.052 & 0.232 & -0.141 & -2.73 \\
\hline 5 & $30^{\circ}$ & 68.0 & 0.655 & 0.104 & 0.189 & -6.22 & -59.7 \\
\hline 5 & $30^{\circ}$ & 38.5 & 0.855 & 0.138 & 0.193 & -21.9 & -158.4 \\
\hline 5 & $60^{\circ}$ & 120.0 & 0.198 & 0.028 & 0.168 & +1.72 & $\begin{array}{r}+60.46\end{array}$ \\
\hline 5 & $60^{\circ}$ & 68.0 & 0.412 & 0.048 & 0.132 & +1.13 & $\begin{array}{r}+23.55 \\
\end{array}$ \\
\hline 5 & $60^{\circ}$ & 38.5 & 0.603 & 0.072 & 0.135 & -8.48 & -118.0 \\
\hline 15 & $0^{\circ}$ & 120.0 & 1.283 & 0.316 & 0.327 & -8.14 & -25.7 \\
\hline 15 & $0^{\circ}$ & 68.0 & 3.017 & 0.688 & 0.295 & -56.2 & -81.7 \\
\hline 15 & $0^{\circ}$ & 38.5 & 3.553 & 0.878 & 0.329 & -107.6 & -122.4 \\
\hline 15 & $30^{\circ}$ & 120.0 & 0.820 & 0.158 & 0.238 & +1.81 & +11.5 \\
\hline 15 & $30^{\circ}$ & 68.0 & 1.959 & 0.320 & 0.196 & -12.7 & -39.5 \\
\hline 15 & $30^{\circ}$ & 38.5 & 2.549 & 0.430 & 0.203 & -53.2 & -124.0 \\
\hline 15 & $60^{\circ}$ & 120.0 & 0.593 & 0.086 & 0.171 & +5.62 & +65.0 \\
\hline 15 & $60^{\circ}$ & 68.0 & 1.234 & 0.146 & 0.135 & +5.17 & +35.4 \\
\hline 15 & $60^{\circ}$ & 38.5 & 1.806 & 0.222 & 0.140 & -19.9 & -89.6 \\
\hline 45 & $0^{\circ}$ & 120.0 & 3.858 & 0.980 & 0.341 & -30.5 & -31.1 \\
\hline 45 & $0^{\circ}$ & 68.0 & 8.985 & 2.154 & 0.315 & -191.8 & -89.1 \\
\hline 45 & $0^{\circ}$ & 38.5 & 10.48 & 2.779 & 0.361 & -314.2 & -113.0 \\
\hline 45 & $30^{\circ}$ & 120.0 & 2.458 & 0.480 & 0.243 & +0.860 & +1.79 \\
\hline 45 & $30^{\circ}$ & 68.0 & 5.855 & 0.990 & 0.204 & -61.8 & -62.4 \\
\hline 45 & $30^{\circ}$ & 38.5 & 7.607 & 1.381 & 0.222 & -199.8 & -144.7 \\
\hline 45 & $60^{\circ}$ & 120.0 & 1.777 & 0.261 & 0.172 & +11.9 & +45.5 \\
\hline 45 & $60^{\circ}$ & 68.0 & 3.684 & 0.443 & 0.137 & +0.531 & +1.20 \\
\hline 45 & $60^{\circ}$ & 38.5 & 5.400 & 0.704 & 0.150 & -86.1 & -122.3 \\
\hline
\end{tabular}

Columns 1, 2, and 3 give the emission index, latitude in degrees, and altitude in millibar of the HSCT perturbation. Column 4 shows the annually averaged increase in atmospheric $\mathrm{NO}_{y}$ loading, in units of $10^{34}$ molecules. Column 5 gives the increase in $\mathrm{NO}_{x}$ loading. Column 6 is the ratio of the increase in active to the increase in inactive chlorine. Column 7 gives the $\mathrm{O}_{3}$ change. Column 8 is column $7 /$ column5, or the number of molecules of $\mathrm{O}_{3}$ added or removed from the atmosphere per additional molecule of $\mathrm{NO}_{x}$.

turbation is stored in inactive forms. This tendency is seen in column 6 , which gives the ratio between active and inactive nitrogen reserviors. This ratio is not a strong function of fleet altitude but decreases by a factor of 2 from low to high latitudes. If this change in partitioning did not occur, the $\mathrm{NO}_{x}$ loading for highlatitude injections would be about a factor of 2 larger. The decrease in sensitivity to HSCT perturbations with latitude of injection would be correspondingly smaller.

Finally, the response of $\mathrm{O}_{3}$ to $\mathrm{NO}_{x}$ depends on the distribution of $\mathrm{NO}_{x}$ in the atmosphere. This can be seen by examining columns 7 and 8 of Table 3 . Column 7 gives the annually averaged atmospheric reduction in $\mathrm{O}_{3}$ molecules from the HSCT perturbation. Column 8 gives the number of $\mathrm{O}_{3}$ molecules lost or gained per $\mathrm{NO}_{x}$ molecule added to the atmosphere. Column 8 ranges from a 160 molecule loss of $\mathrm{O}_{3}$ per added $\mathrm{NO}_{x}$ molecule for an equatorial high-altitude fleet to an over 60 molecule $\mathrm{O}_{3}$ gain per added $\mathrm{NO}_{x}$ molecule when the injection is at high latitudes and low altitudes.

It is interesting to compare the $\mathrm{O}_{3}$ and $\mathrm{NO}_{y}$ distributions resulting from the different fleet dispositions. Figure $2 \mathrm{a}$ shows the percent change in column $\mathrm{O}_{3}$ as a function of season and latitude for the $\mathrm{EI}=45$, low-latitude, high-altitude fleet $\left(0^{\circ}, 38.5 \mathrm{mbar}\right)$. This run shows the largest $\mathrm{O}_{3}$ response for the middle background chlorine and sulfate levels. Maximum column reductions of over $12 \%$ occur at the poles in late winter. The minimum reductions of about $5 \%$ occur in the high tropics in the northern and southern hemisphere autumns.

The percent increase in column $\mathrm{NO}_{2}$ that occurs during this run is shown in Figure 2b. This gives a reasonable idea of the changes in active odd nitrogen that occur with the addition of the aircraft fleet emissions. Increases of over $150 \%$ occur at the equator and decrease poleward. The annual amplitude is small in the tropics and increases toward the poles. The maximum polar reductions in column $\mathrm{O}_{3}$ seen in Figure 2a correlate with the maximum increases in column $\mathrm{NO}_{2}$ at the poles.

A very different picture is seen for the column $\mathrm{O}_{3}$ and $\mathrm{NO}_{2}$ changes resulting from a low-altitude, highlatitude fleet location. Figures $3 \mathrm{a}$ and $3 \mathrm{~b}$ show these changes for the $\mathrm{EI}=45,60^{\circ} \mathrm{N}, 120-\mathrm{mbar}$ case. In this case, $\Delta G \mathrm{O}_{3}^{\mathrm{HSCT}}$ increases by $+0.25 \%$. This increase occurs because the entire northern hemisphere shows increases in column $\mathrm{O}_{3}$, with maximum increases occurring in late summer/early autumn. The maximum decrease occurs in the southern hemisphere fall and is less than $0.3 \%$. The column $\mathrm{NO}_{2}$ changes that occur 

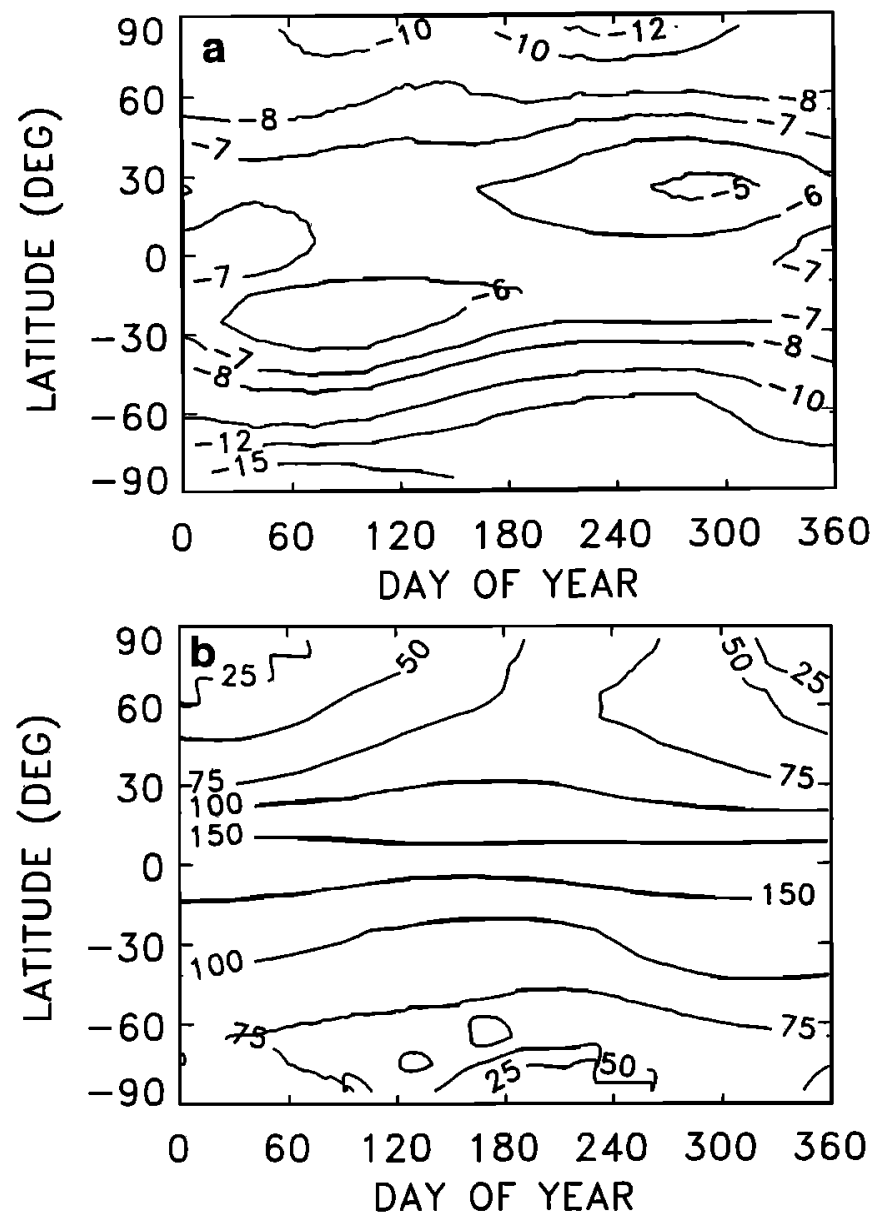

Figure 2. (a) Percent change in column $\mathrm{O}_{3}$ as a function of day and latitude for the low-latitude, highaltitude fleet injection location $\left(0^{\circ}, 38.5 \mathrm{mbar}\right)$. The emission index (EI) for this case is 45 . (b) Percent change in column $\mathrm{NO}_{2}$ as a function of day and latitude that occurs for this case.

for this case (Figure $3 \mathrm{~b}$ ) show northern hemisphere increases that are up to a factor of 8-10 larger than the smaller southern hemisphere column $\mathrm{NO}_{2}$ increases of about $2 \%$. Overall, however, the $\mathrm{NO}_{2}$ increases are much smaller in this case than with the fleet location at low latitude and high altitude. At the south pole the maximum increase occurs in the southern hemisphere fall and is correlated with the maximum southern hemisphere $\mathrm{O}_{3}$ decrease seen in Figure 3a. Maximum increases in the northern hemisphere of about $20 \%$ are located in the northern hemisphere summer/fall at about $60^{\circ} \mathrm{N}$. Instead of being correlated with the maximum decreases in $\mathrm{O}_{3}$, however, they are correlated with the maximum increases in column $\mathrm{O}_{3}$.

Comparison of Figures 2 and 3 reveals the following differences between the two cases: (1) Column $\mathrm{NO}_{2}$ increases (and therefore stratospheric $\mathrm{NO}_{x}$ concentrations) are much larger for the low-latitude, high-altitude fleet location. The distribution of the increase is relatively symmetric about the equator in the low-latitude case. (2) In the low-latitude case, column $\mathrm{O}_{3}$ decreases when column $\mathrm{NO}_{2}$ increases. In the high-latitude case, the southern hemisphere column $\mathrm{O}_{3}$ decreases when column $\mathrm{NO}_{2}$ increases, but in the northern hemisphere there are positive correlations between column $\mathrm{NO}_{2}$ and $\mathrm{O}_{3}$.

Further information about the-differences between the low-latitude, high-altitude, and the low-altitude, high-latitude cases can be obtained by looking at latitude/altitude cross sections of the changes in $\mathrm{O}_{3}$ and $\mathrm{NO}_{x}$. Figure 4a shows the percentage change in $\mathrm{O}_{3}$ for the low-latitude, high-altitude fleet location, in September. Maximum local reductions form a trough that extends from the equator to the poles. The trough altitude is located at about $10 \mathrm{mbar}$ at the equator and dips to between 20 and $30 \mathrm{mbar}$ over the poles. Reductions of over $30 \%$ occur along this trough. There is a clear signature of self-healing in the tropics at about 50 mbar, where the $\mathrm{O}_{3}$ increases by up to $15 \%$. The changes in $\mathrm{NO}_{x}$ responsible for the $\mathrm{O}_{3}$ loss are shown in Figure 4b. The maximum increase in $\mathrm{NO}_{x}$ of over 13 ppbv occurs in the tropics at $10 \mathrm{mbar}$, colocated with the site of maximum reductions in $\mathrm{O}_{3}$.


Figure 3. (a) Percent change in column $\mathrm{O}_{3}$ as a function of day and latitude for the high-latitude, lowaltitude fleet injection location $\left(60^{\circ} \mathrm{N}, 120 \mathrm{mbar}\right)$. The EI for this case is 45 . (b) Percent change in column $\mathrm{NO}_{2}$ as a function of day and latitude that occurs for this case. 

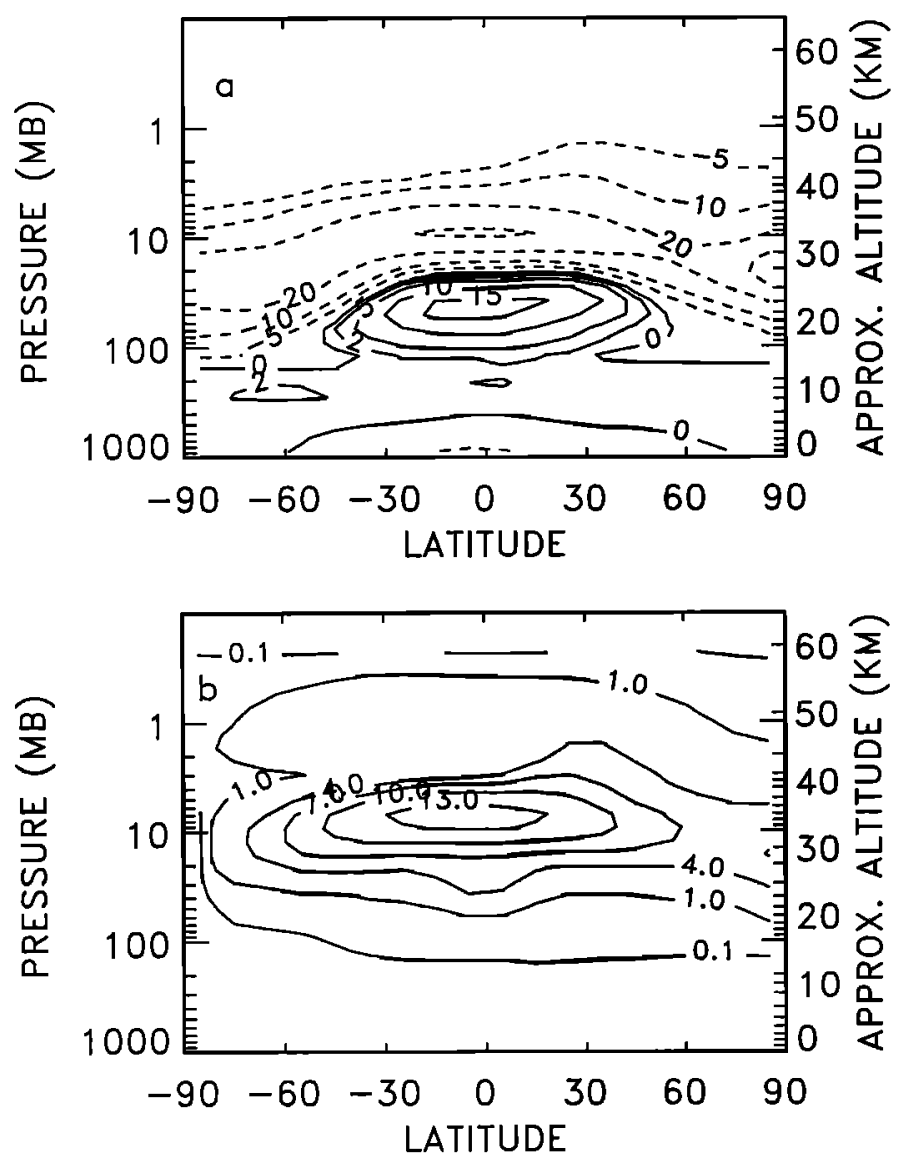

Figure 4. (a) Percent change in $\mathrm{O}_{3}$ from the aircraft perturbation as a function of latitude and pressure, for September. The fleet is at the low-latitude, high-altitude location $\left(0^{\circ}, 38.5 \mathrm{mbar}\right)$. The $\mathrm{EI}=45$ and middle values of chlorine and background aerosols were used. (b) Change in $\mathrm{NO}_{x}\left(\mathrm{NO}_{x}=\mathrm{NO}+\mathrm{NO}_{2}\right)$, in parts per billion by volume (ppbv), for the same conditions as Figure $4 \mathrm{a}$.

Figure $5 \mathrm{a}$ shows the changes in $\mathrm{O}_{3}$ in September, for the low-altitude, high-latitude fleet. The $\mathrm{O}_{3}$ losses are a factor of 30 smaller than in the previous case (Figure $4 \mathrm{a}$ ) but have the same spatial distribution. The northern hemisphere troposphere and lower stratosphere is characterized by $\mathrm{O}_{3}$ increases of up to $5 \%$. At $60^{\circ} \mathrm{N}, \mathrm{O}_{3}$ increases occur up to about 50 mbar. In the low-latitude, high-altitude case the increases turn to losses at significantly lower altitudes, between 100 and $200 \mathrm{mbar}$. Figure $5 \mathrm{~b}$ shows the $\mathrm{NO}_{x}$ increases for Figure $5 \mathrm{a}$. The plot shows two peaks in the $\mathrm{NO}_{x}$ increase. Note that the $\mathrm{NO}_{y}$ increase does not show a double-peaked distribution. It peaks at the location of the HSCT fleet and decreases away from it. The $\mathrm{NO}_{x}$ increase is doublepeaked because the $\mathrm{NO}_{x} / \mathrm{NO}_{y}$ ratio increases toward the equator, so an inceasing fraction of the increase in $\mathrm{NO}_{y}$ is in the form of $\mathrm{NO}_{x}$. This results in an equatorial increase in $\mathrm{NO}_{x}$ of about $0.3 \mathrm{ppbv}$ at $10 \mathrm{mbar}$, over 40 times smaller than the peak increases in $\mathrm{NO}_{x}$ seen in Figure $4 \mathrm{~b}$. The approximately $0.6 \mathrm{ppbv}$ lower stratosphere/upper troposphere peak in the northern hemisphere high latitudes seen in Figure $5 \mathrm{~b}$ is about 6 times the increase in $\mathrm{NO}_{x}$ seen at this location in Figure $4 \mathrm{~b}$. This northern hemisphere peak is in a location where hydrocarbon chemistry is important, so increases in $\mathrm{NO}_{x}$ increase rather than decrease $\mathrm{O}_{3}$.

In both cases examined above, the $\mathrm{O}_{3}$ losses are occurring in the same place: the midstratosphere around 10 to 30 mbar. The difference between the two fleet locations that produces such large differences in $\mathrm{O}_{3}$ loss is the amount of $\mathrm{NO}_{x}$ that gets transported to the loss region; the ratio between the local percent $\mathrm{O}_{3}$ loss and $\mathrm{NO}_{x}$ increase is similar in both cases. This large sensitivity of $\mathrm{O}_{3}$ loss to fleet location raises a concern about the nature of the model transport processes and how well they correspond to average transport in the real atmosphere. Jackman et al. [1991] noted a very large sensitivity of HSCT-induced $\mathrm{O}_{3}$ depletion predictions to different two-dimensional model transport parameterizations. Douglass et al. [1993] compared tracer tranport in a three-dimensional and a two-dimensional model and found significant differences. Compared to the two-dimensional model, the three-dimensional model circulation exhibited more vigorous horizontal and vertical tracer transport. Clearly,
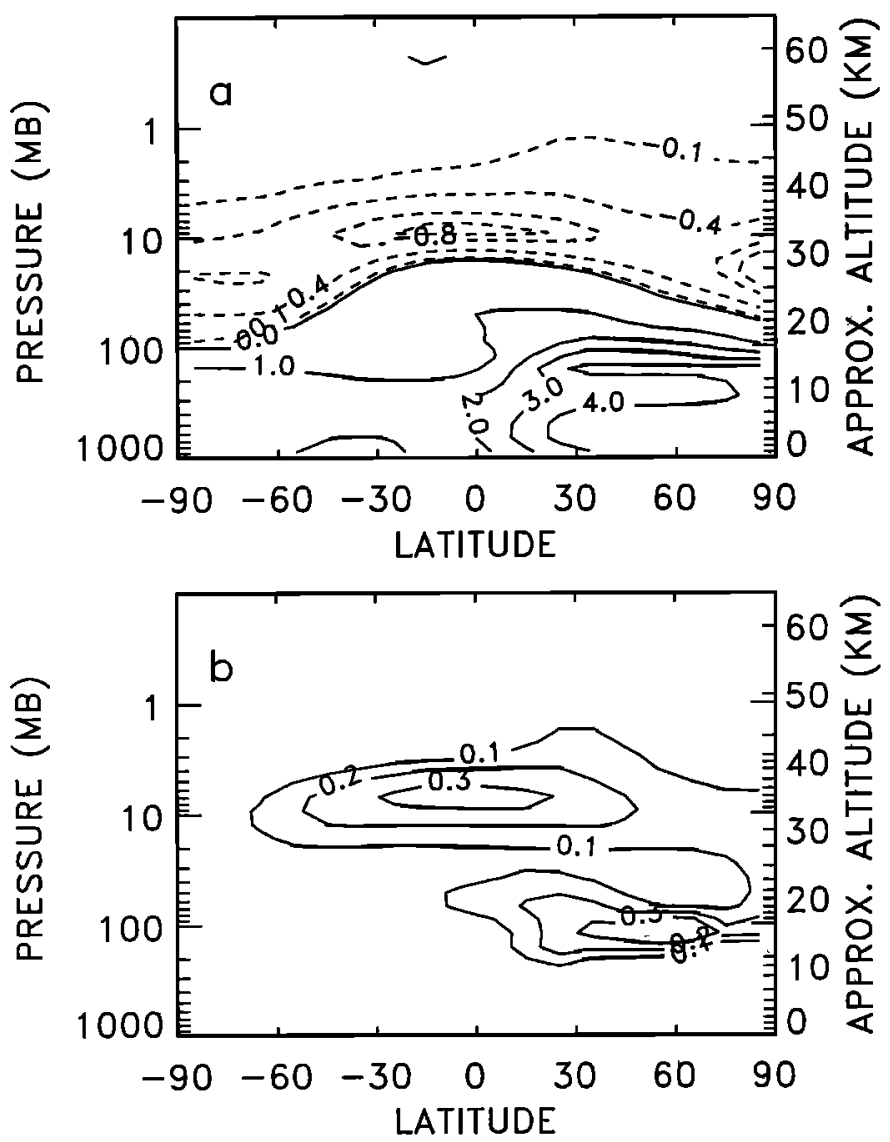

Figure 5. (a) Percent change in $\mathrm{O}_{3}$ from the aircraft perturbation as a function of latitude and pressure, for September. The fleet is at the high-latitude, low-altitude location $\left(60^{\circ} \mathrm{N}, 120\right.$ mbar). The $\mathrm{EI}=45$, and middle values of chlorine and background aerosols were used. (b) Change in $\mathrm{NO}_{x}\left(\mathrm{NO}_{x}=\mathrm{NO}+\mathrm{NO}_{2}\right)$, in ppbv, for the same conditions as Figure 5a. 
if the two-dimensional model had more vigorous horizontal and vertical transport, there would be less isolation of the $\mathrm{O}_{3}$ loss region mentioned above to the emissions of a high-latitude fleet. In such a situation there would be less of a difference in impact on $\mathrm{O}_{3}$ between fleets with different locations.

The results of this study reinforce the observation that transport processes may be a large source of model error. They also suggest that not all fleet dispositions are equal. A fuel efficient fleet with low emissions in one location may be a source of more $\mathrm{O}_{3}$ loss than a more polluting one that flies at higher latitudes and lower altitudes.

\section{Effects of Changes in Fleet Location on $\mathrm{H}_{2} \mathrm{O}$ and $\mathrm{HO}_{x}$}

Changes in fleet location also have a large impact on the HSCT-induced increase in $\mathrm{H}_{2} \mathrm{O}$. Figures 6a and $6 \mathrm{~b}$ show the September increase in $\mathrm{H}_{2} \mathrm{O}$ caused by the HSCT fleet for the low-latitude, high-altitude and high-latitude, low-altitude cases, respectively. The maximum increase in $\mathrm{H}_{2} \mathrm{O}$ for the low-latitude, highaltitude injection is about 1.5 parts per million by vol-


Figure 6. (a) September increase in $\mathrm{H}_{2} \mathrm{O}$ from the aircraft emissions, in parts per million by volume (ppmv). The fleet is at the low-latitude, high-altitude location $\left(0^{\circ}, 38.5 \mathrm{mbar}\right)$. (b) Same as Figure $6 \mathrm{a}$, with the fleet at the high-latitude, low-altitude location $\left(60^{\circ} \mathrm{N}, 120\right.$ mbar).
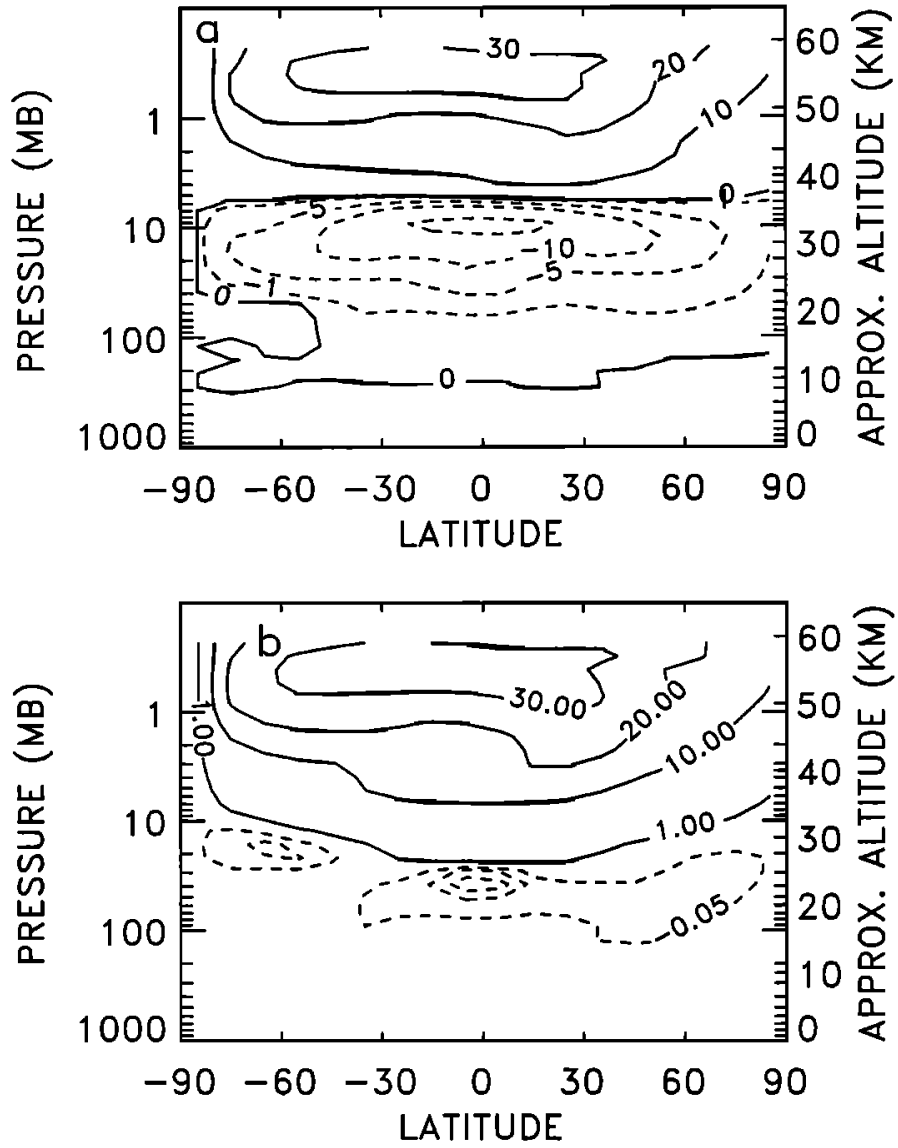

Figure 7. (a) September changes in $\mathrm{HO}_{x}\left(\mathrm{HO}_{x}=\right.$ $\mathrm{H}+\mathrm{OH}+\mathrm{HO}_{2}$ ) from the aircraft emissions, in parts per trillion by volume (pptv). The fleet is at the lowlatitude, high-altitude location $\left(0^{\circ}, 38.5 \mathrm{mbar}\right)$, and has an $E I=45$. (b) Same as Figure 7a, for $E I=5$.

ume (ppmv), occurring at the equator at about 40 mbar. Fairly large increases in water vapor occur throughout the stratosphere with a band of over $0.8 \mathrm{ppmv}$ increases extending from pole to pole. The increases are fairly symmetrically distributed between the northern and southern hemispheres. In contrast, the high-latitude, low-altitude injection location produces a smaller and much more unevenly distributed $\mathrm{H}_{2} \mathrm{O}$ increase. Southern hemisphere increases do not exceed $0.03 \mathrm{ppmv}$. The northern hemisphere distribution peaks at $60^{\circ}$ and 120 mbar (the central latitude and pressure level of the fleet location). Maximum increases of about $0.4 \mathrm{ppmv}$ occur here but are confined to the lower stratosphere.

The changes in $\mathrm{HO}_{x}$ from the HSCT perturbations are complicated and depend sensitively on the amount of $\mathrm{NO}_{x}$ deposited by the fleet. Figures $7 \mathrm{a}$ and $7 \mathrm{~b}$ show the change in $\mathrm{HO}_{x}$ for the low-latitude, high-altitude fleet location. Fleet emissions at this location produce the largest increases in $\mathrm{H}_{2} \mathrm{O}$ vapor. Figure 7 a shows the change in parts per trillion by volume (pptv) for the $\mathrm{EI}=45$ case, while Figure $7 \mathrm{~b}$ shows the $\mathrm{HO}_{x}$ change for the $\mathrm{EI}=5$ case. The equatorial midstratosphere is characterized by $\mathrm{HO}_{x}$ decreases of up to 20 pptv in the $\mathrm{EI}=45$ case and up to 1 pptv in the $\mathrm{EI}=5$ case. $\mathrm{HO}_{x}$ 
decreases in the lower stratosphere even though $\mathrm{H}_{2} \mathrm{O}$ increases because $\mathrm{HO}_{x}$ production also depends on $\mathrm{O}_{x}$ $\left(\mathrm{O}_{x}=\mathrm{O}_{3}+\mathrm{O}+\mathrm{O}\left({ }^{1} \mathrm{D}\right)\right)$, which is reduced by the HSCT perturbation. In the upper stratosphere where the $\mathrm{O}_{x}$ decrease from the $\mathrm{HSCT} \mathrm{NO}_{x}$ is small, the $\mathrm{H}_{2} \mathrm{O}$ from the HSCT fleet increases $\mathrm{HO}_{x}$. The increase is similar in both cases. The partitioning of $\mathrm{HO}_{x}$ depends on both $\mathrm{O}_{x}$ and $\mathrm{NO}_{x}$, and this will also affect the response of $\mathrm{HO}_{x}$ to the HSCTs. This lower stratospheric decrease in $\mathrm{HO}_{x}$ reduces the loss of $\mathrm{O}_{3}$ due $\mathrm{HO}_{x}$ catalysis. The larger the increase in $\mathrm{NO}_{x}$, the more pronounced the reduction in $\mathrm{HO}_{x}$ and $\mathrm{HO}_{x}$ loss.

The response of $\mathrm{HO}_{x}$ to the HSCTs indicates that the large increases in $\mathrm{H}_{2} \mathrm{O}$ produced by the HSCTs do not have a large impact on $\mathrm{O}_{3}$. It should be noted that this conclusion does not consider the effects of PSCs. However, Pitari et al. [1993] and Considine et al. [1994] have found that PSCs reduce the sensitivity of the model to HSCT perturbations slightly, so it is likely that the effects of $\mathrm{H}_{2} \mathrm{O}$ emissions on $\mathrm{O}_{3}$ are small even when PSCs are considered.

\section{Effects of Changes in Aerosol and Chlorine}

The rates of the heterogeneous reactions (reactions (1), (2), and (3)) are increased by increases in the SSA surface area density. These reactions have two basic effects. First, they convert active odd nitrogen to reservoir forms. Second, reservoir chlorine is converted to active chlorine. The chlorine repartitioning happens either by direct conversion of inactive to active chlorine with reactions (1) and (2) or indirectly from the odd nitrogen repartitioning, as with reaction (3). The repartitioning reduces the fraction of total $\mathrm{O}_{3}$ loss that is caused by $\mathrm{NO}_{x}$ species and increases the role of odd chlorine. Increases in $\mathrm{NO}_{x}$ under these conditions have less of an impact on $\mathrm{O}_{3}$. A model with higher heterogeneous reaction rates will be less sensitive to HSCT perturbations; as aerosol surface area densities decrease, model sensitivity will increase [Weisenstein et al., 1993].

Decreases in background chlorine levels should also increase the impact of the HSCT perturbation. The mechanism is essentially the same as described above. Lower amounts of background chlorine such as might occur late in the next century will result in less of the HSCT perturbation being converted to inactive $\mathrm{ClONO}_{2}$ so $\mathrm{NO}_{x}$ increases will be larger. Also, the relative importance of chlorine loss processes in the $\mathrm{O}_{3}$ budget is smaller, so the role of $\mathrm{NO}_{x}$ will be larger, also increasing the model sensitivity to HSCTs [Johnston et al., 1989; Weisenstein et al., 1991; Ko and Weisenstein, 1992; Ko and Douglass, 1993].

Thus the impact of changes in aerosol and background chlorine levels is related to their effect on lower stratospheric $\mathrm{Cl}_{x}\left(\mathrm{Cl}_{x}=\mathrm{Cl}+\mathrm{ClO}\right)$. Figures $8 \mathrm{a}$ and $8 \mathrm{~b}$ show the change in lower stratospheric $\mathrm{Cl}_{x}$ for variations in background chlorine and aerosol levels, respectively. The plot is for September at $55^{\circ} \mathrm{N}$. A factor of 3 increase in $\mathrm{Cl}_{x}$ occurs for the variation in background chlorine, while a factor of 4 increase in background aerosols increases $\mathrm{Cl}_{x}$ by about a factor of 2 at midlatitudes.
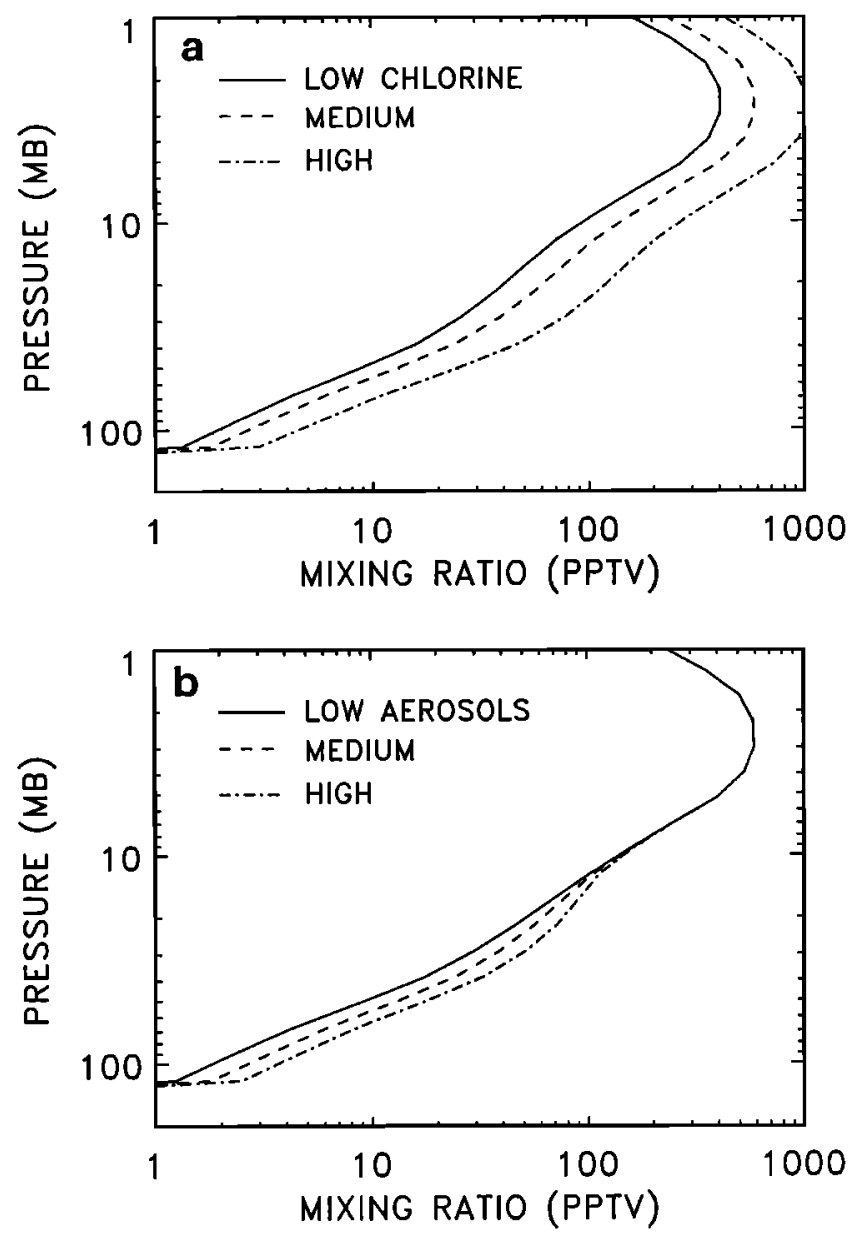

Figure 8. (a) Increase in lower stratospheric active chlorine due to increases in background chlorine levels. Shown is $\mathrm{Cl}_{x}(=\mathrm{Cl}+\mathrm{ClO})$ as a function of pressure at $55^{\circ} \mathrm{N}$ in September. The low chlorine case corresponds to $1.4 \mathrm{ppbv}$ total chlorine, the medium case corresponds to $2.0 \mathrm{ppbv}$, and the high case to $3.7 \mathrm{ppbv}$ background chlorine. (b) Increase in lower stratospheric active chlorine due to increases in background aerosol levels. The location and time is the same as Figure 8a The low aerosol case corresponds to $f=1$, medium corresponds to $f=2$, and the high aerosol case corresponds to $f=4$. Here, $f$ is the prefactor applied to the basic stratospheric sulfate aerosol (SSA) distribution described in the text.

Figure $9 \mathrm{a}$ shows the response of global total $\mathrm{O}_{3}$ to increases in the aerosol and chlorime loading of the atmosphere. This plot is for a fleet located at low latitudes $\left(0^{\circ}\right)$ and high altitudes (38.5 mbar), with an emission index of 45. From this plot it is easy to see that increasing aerosol loading reduces the $\mathrm{O}_{3}$ depletion for all chlorine levels. The largest sensitivity of $\Delta G \mathrm{O}_{3}^{\mathrm{HSCT}}$ to aerosols occurs for low aerosol amounts, with $\Delta G \mathrm{O}_{3}^{\mathrm{HSCT}}$ reduced by a factor of about $1 / 3$ as the aerosol background increases from no aerosols to the $f=1$ case. The response of $\Delta G \mathrm{O}_{3}^{\mathrm{HSCT}}$ to further increases in aerosols flattens out for higher aerosol amounts. The figure also shows that increasing background chlorine also reduces $\mathrm{O}_{3}$ depletion. The reduction in $\Delta G \mathrm{O}_{3}^{\mathrm{HSCT}}$ resulting from an increase in aerosols from $f=1$ to $f=4$ is larger than the 

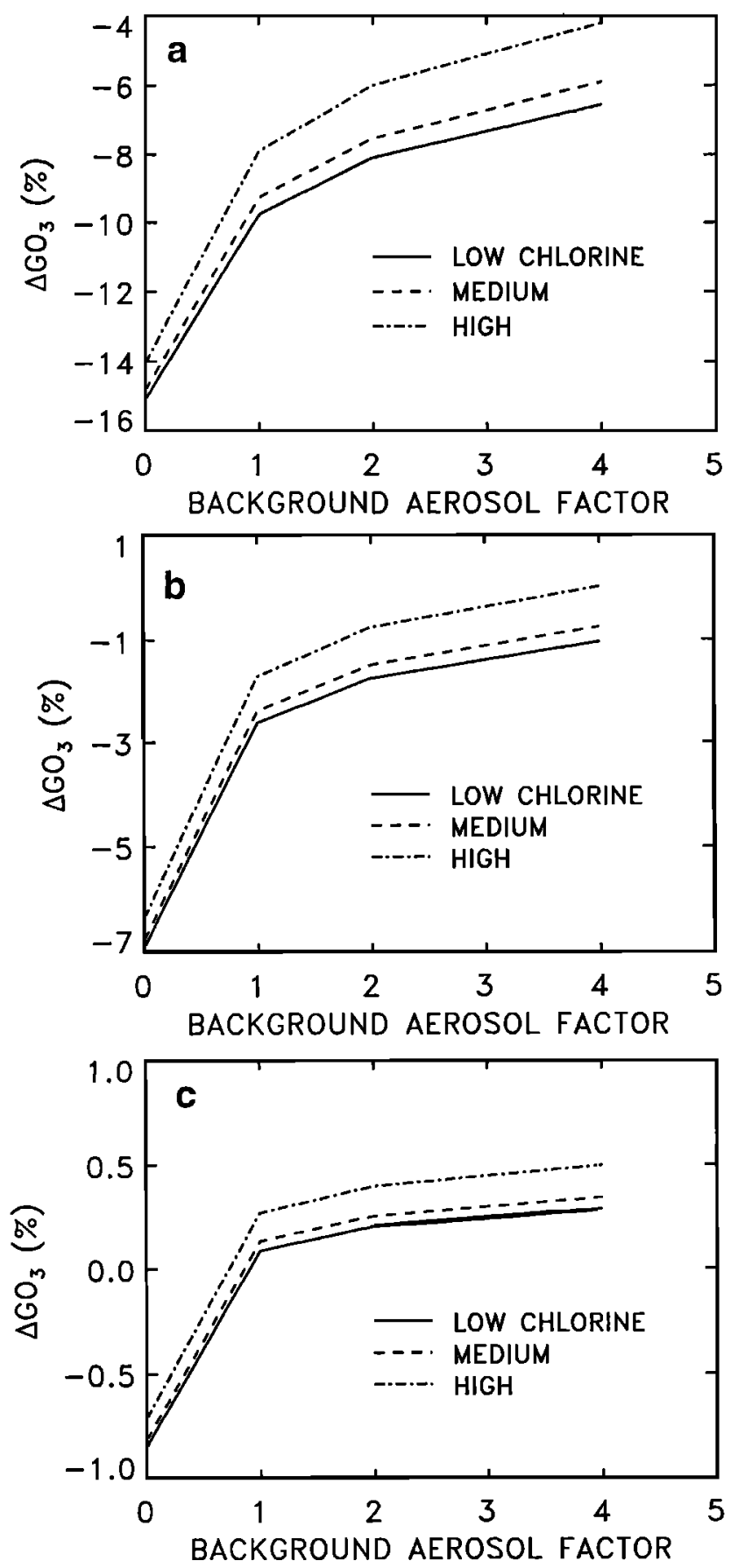

Figure 9. (a) Change in globally and anually averaged column ozone ( $\left.\Delta G \mathrm{O}_{3}^{\mathrm{HSCT}}\right)$ with background aerosols and chlorine loading. $\Delta G \mathrm{O}_{3}^{\mathrm{HSCT}}$ is the percent change when the HSCT fleet emissions occur at the low-latitude, high-altitude location $\left(0^{\circ}, 38.5 \mathrm{mbar}\right)$, for an emission index of 45 . The background aerosol factor is applied to the basic sulfate aerosol distribution to adjust its magnitude. (b) Same as Figure 9a, for a middle-latitude, middle-altitude fleet location $\left(30^{\circ} \mathrm{N}\right.$, $68 \mathrm{mbar}$ ). (c) Same as Figure 9a, for the high-latitude, low-altitude fleet location $\left(60^{\circ} \mathrm{N}, 120 \mathrm{mbar}\right)$.

reduction caused by the increase in background chlorine levels. This is interesting because lower stratospheric active chlorine increases more from the change in background chlorine than the change in aerosols, as shown in
Figures $8 \mathrm{a}$ and $8 \mathrm{~b}$. Increases in background chlorine do not produce as much of a reduction in $\mathrm{NO}_{x}$ as aerosol increases do. Because the aerosols both reduce $\mathrm{NO}_{x}$ and increase $\mathrm{Cl}_{x}$, they can have a greater impact on $\Delta G \mathrm{O}_{3}^{\mathrm{HSCT}}$ even though the increases in $\mathrm{Cl}_{x}$ are smaller than occur by increasing the chlorine background.

Figure $9 \mathrm{a}$ also shows that the sensitivity of $\Delta G \mathrm{O}_{3}^{\mathrm{HSC} T}$ to increases in aerosol is slightly modified at higher chlorine levels. For instance, the decrease in $\Delta G \mathrm{O}_{3}^{\mathrm{HSCT}}$ between the $f=2$ and $f=4$ cases is marginally greater for higher chlorine than the lower chlorine background. The effect is not very large, however. The same holds true for the sensitivity of $\Delta G \mathrm{O}_{3}^{\mathrm{HSCT}}$ to increases in chlorine: there is a small increase in the response with changing increasing aerosol loading.

Figures $9 \mathrm{~b}$ and $9 \mathrm{c}$ show the response of $\Delta G \mathrm{O}_{3}^{\mathrm{HSCT}}$ to changes in chlorine and aerosol loading for higherlatitude, lower-altitude fleet locations. In Figure $9 \mathrm{~b}$ the fleet is at $30^{\circ} \mathrm{N}, 68 \mathrm{mbar}$ and in Figure $9 \mathrm{c}$ the location is $60^{\circ} \mathrm{N}, 120$ mbar. The qualitative features of Figure $9 \mathrm{a}$ are preserved although there are large changes in the absolute values of $\Delta G \mathrm{O}_{3}^{\mathrm{HSCT}}$ and the variation from low to high levels of aerosol and chlorine loading.

Column 8 of Table 3 lists the change in the number of $\mathrm{O}_{3}$ molecules in the atmosphere per additional molecule of $\mathrm{NO}_{x}$ added by the stratospheric aircraft. The table shows that the response of $\mathrm{O}_{3}$ depends sensitively on the location of the aircraft fleet. Figures 10a-10d show how this relationship changes as chlorine and aerosol levels in the model change. Figure 10a shows the relationship for the $\mathrm{EI}=5$, low background chlorine, low background aerosol condition. At the highest injection altitudes the response of the model is not very sensitive to changes in fleet latitude. At the lowest altitudes the sensitivity to changes in latitudes is a maximum. Figure 10b shows the relationship for the high background chlorine, low aerosol case. For high-altitude injections there has been a significant decrease in model sensitivity. The change is somewhat less for the low-altitude injection. Figure 10c shows the low chlorine, high aerosol case. This figure is very similar to Figure $10 \mathrm{a}$, showing that aerosol effects are most important in high chlorine environments. Figure 10d shows the combined effects of both high chlorine and high aerosol backgrounds. This case exhibits the largest range of fleet locations which produce increases in $\mathrm{O}_{3}$ from the aircraft fleet. At low fleet altitudes, however, the change in the HSCT impact on $\mathrm{O}_{3}$ varies with fleet latitude about as much in this case as in the other three. At high injection altitudes the variation with fleet latitude is somewhat greater.

The large sensitivity of $\Delta G \mathrm{O}_{3}^{\mathrm{HSC} T}$ at low aerosol loading ( $f=0$ to $f=1$ ) indicates uncertainty in the response of $\Delta G \mathrm{O}_{3}^{\mathrm{HSCT}}$ during volcanically quiescent periods. This is especially so if the true SSA background is smaller than the $f=1$ case that is assumed to represent background conditions in this study. Toon et al. [1979] concluded that the sulfate aerosol at that time could be accounted for by observed concentrations of tropospheric OCS and $\mathrm{SO}_{2}$. This suggests that the $f=1$ case does represent a volcanically unperturbed situation and minimal SSA surface area densities. A 

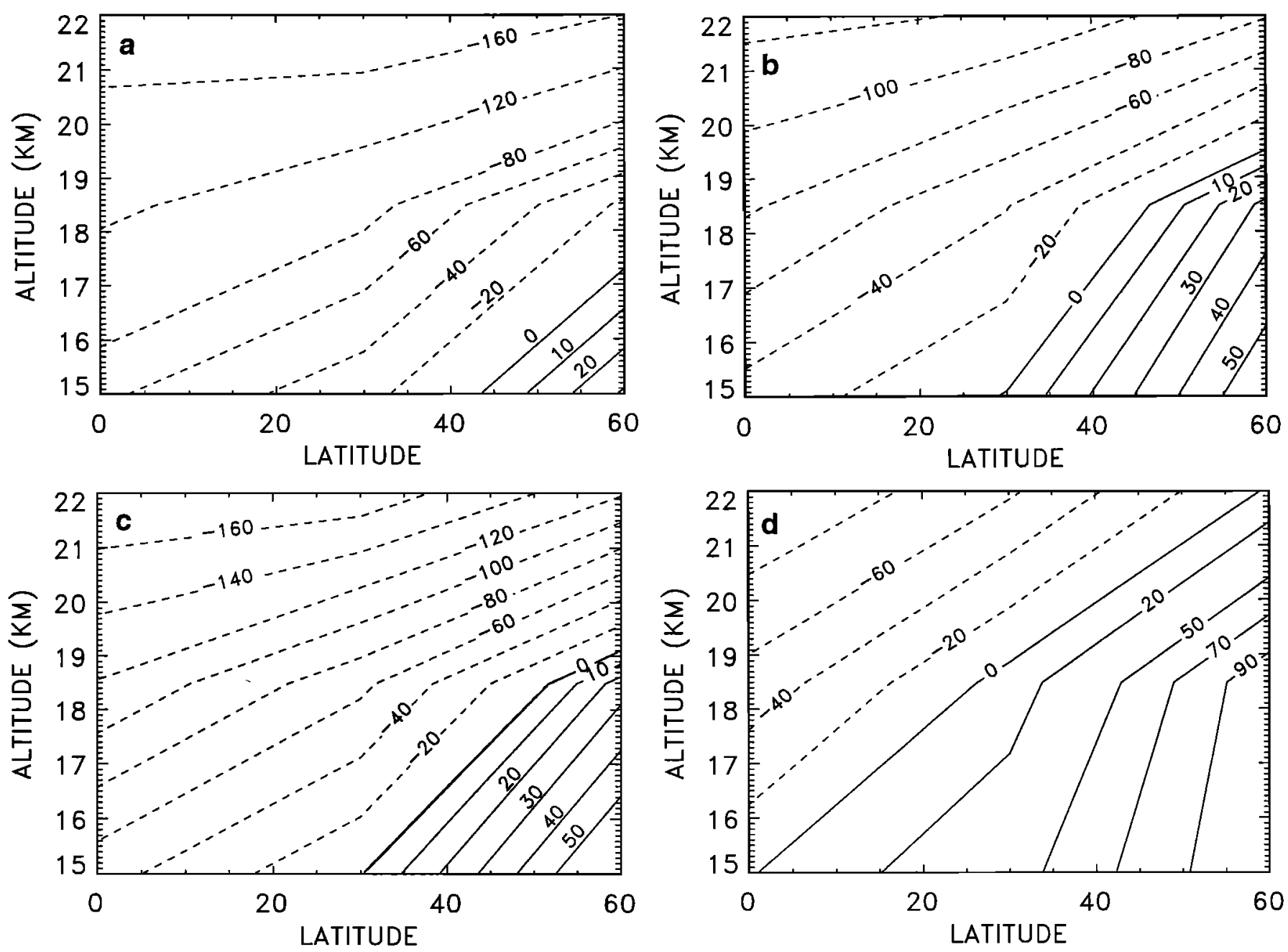

Figure 10. Ratio of the globally and annually averaged change in $\mathrm{O}_{3}$ molecules to the annually and globally averaged increase in atmospheric $\mathrm{NO}_{x}$ molecules due to the HSCT fleet, as a function of fleet latitude and altitude. The quantity can be thought of as the number of molecules of $\mathrm{O}_{3}$ created or destroyed per molecule increase in the atmospheric $\mathrm{NO}_{x}$ burden by the HSCTs. The fleet emission index is 5 in all cases. (a) The ratio under low chlorine and low aerosol background conditions. (b) The ratio with the high chlorine and low aerosol background conditions. (c) The ratio under low chlorine and high aerosol background conditions. (d) The ratio with both high chlorine and high aerosol backgrounds.

more recent study concludes that OCS oxidation is a 2-7 times smaller source of stratospheric sulfur than previous estimates [Davis and Chin, 1993]. This study concludes that volcanic sources or an as yet unknown source of sulfur is needed to produce the stratospheric sulfate levels that are considered to be background values. If this is the case, then $f<1$ conditions may possibly occur in volcanically quiet periods.

\section{Effects of Changes in Reaction Rates}

In the sections above, the role of variations in fleet location and emissions, background chlorine levels, and sulfate aerosol loading on model $\mathrm{O}_{3}$ depletion predictions have been examined. To the extent that the model accurately characterizes the response of the real atmosphere, a prediction of the effects of an HSCT fleet for a specific set of atmospheric conditions is obtained. How- ever, since the exact nature of the HSCT fleet and the atmosphere in which it might fly is unknown, this is not the most useful product of these calculations. The most useful information obtained from the calculations is an estimate of the model sensitivity to parameter variations and uncertainty in the model predictions due to uncertain values for the various parameters.

Another potentially large source of model prediction uncertainty is $\mathrm{HO}_{x}$-catalyzed $\mathrm{O}_{3}$ loss. $\mathrm{HO}_{x}$ species play a major role in upper tropospheric and lower stratospheric $\mathrm{O}_{3}$ chemistry. This section examines the changes in $\mathrm{O}_{3}$ depletion predictions that occur when two key reactions involving $\mathrm{HO}_{x}$ are varied over their ranges of uncertainty. These two reactions are:

$$
\begin{aligned}
\mathrm{HO}_{2}+\mathrm{NO} & \rightarrow \mathrm{NO}_{2}+\mathrm{OH} \\
\mathrm{HO}_{2}+\mathrm{O}_{3} & \rightarrow \mathrm{OH}+2 \mathrm{O}_{2} .
\end{aligned}
$$





Figure 11. (a) Change in globally and anually averaged column ozone $\left(\triangle G \mathrm{O}_{3}^{\mathrm{HSCT}}\right)$ with emission index, at three different values of the reaction $\mathrm{NO}+\mathrm{HO}_{2} \rightarrow$ $\mathrm{NO}_{2}+\mathrm{OH}$ The " $-\sigma$ " and " $+\sigma$ " cases are the values of the reaction rate at the lower and upper uncertainty limits, as given by DeMore et al. [1992]. The "nominal" case is the best estimate of this reaction rate, as given by DeMore et al. [1992]. The fleet is located at the low-latitude, high-altitude position $\left(0^{\circ}, 38.5 \mathrm{mbar}\right)$. (b) Same as Figure 11a, for a middle-latitude, middlealtitude fleet location $\left(30^{\circ} \mathrm{N}, 68\right.$ mbar). (c) Same as Figure 11a, for the high-latitude, low-altitude fleet location $\left(60^{\circ} \mathrm{N}, 120 \mathrm{mbar}\right)$.
Reaction (7) couples the $\mathrm{NO}_{x}$ and $\mathrm{HO}_{x}$ cycles. It is part of a null cycle for $\mathrm{HO}_{x}$ and participates in a reaction chain that produces $\mathrm{O}_{x}$ from $\mathrm{CH}_{4}$ oxidation. It is reasonable to suspect that HSCT-induced $\mathrm{O}_{3}$ depletion might be sensitive to the rate of this reaction. Reaction 8 is an important player in $\mathrm{HO}_{x}$ and the rate of this reaction has a large uncertainty associated with it. At $220 \mathrm{~K}$ the uncertainty limits of this reaction are $0.42 k<k<1.46 k$, where $k$ is the nominal reaction rate [DeMore et al., 1992].

To test the sensitivity of the $\mathrm{O}_{3}$ depletion predictions to these two rates, 112 model runs were conducted in addition to those made for the previous sections. The low background sulfate loading and medium background chlorine conditions were used and were the same in all of the runs. Each reaction was set in turn to its lower or upper uncertainty limits. Model runs were made for all combinations of fleet location and emission index. Thus for each reaction rate combination examined, 28 runs ( 1 base and 27 perturbed cases) were calculated.

Figure 11a shows the response of $\Delta G \mathrm{O}_{3}^{H S C T}$ to changes in emission index with the $\mathrm{NO}+\mathrm{HO}_{2}$ reaction varied over its uncertainty limits. The fleet is at the lowlatitude, high-altitude location. The reaction rate and $\Delta G \mathrm{O}_{3}^{\mathrm{HSCT}}$ are anticorrelated for all emission indices. The sensitivity of $\Delta G \mathrm{O}_{3}^{\mathrm{HSCT}}$ to changes in the reaction rate is small and relatively independent of emission index. Figures $11 \mathrm{~b}$ and $11 \mathrm{c}$ show the same plot as Figure 11a at higher latitudes and lower altitudes. The same conclusions apply here as were obtained from Figure 11a. The uncertainty in $\Delta G \mathrm{O}_{3}^{\mathrm{HSCT}}$ due to uncertainty in the $\mathrm{NO}+\mathrm{HO}_{2}$ reaction rate is very small when compared with the response of $\triangle G \mathrm{O}_{3}^{\mathrm{HSCT}}$ to changes in background aerosol and chlorine loading seen in Figure 9.

Figures $12 a, 12 b$, and $12 c$ show the results for variations in the $\mathrm{O}_{3}+\mathrm{HO}_{2}$ reaction rate. Again, the same general conclusions can be drawn about this reaction as was for $\mathrm{NO}+\mathrm{HO}_{2}$. Somewhat greater uncertainty exists in $\Delta G \mathrm{O}_{3}^{\mathrm{HSCT}}$ due to uncertainties in this reaction, especially at the highest emission index. However, compared to the response of $\Delta G \mathrm{O}_{3}^{\mathrm{HSCT}}$ to changes in aerosol loading and chlorine background, this uncertainty is relatively small.

It is instructive to compare the effects of increasing the rate of $\mathrm{HO}_{2}+\mathrm{O}_{3} \rightarrow \mathrm{OH}+2 \mathrm{O}_{2}$ with the effects of increasing the background aerosol loading of the model. In the reaction rate case, base $\mathrm{O}_{3}$ amounts change from 311.8 Dobson units (DU) with the rate at $k_{\mathrm{HO}_{2}, \mathrm{O}_{3}}-\sigma$ to $293.1 \mathrm{DU}$ at $k_{\mathrm{HO}_{2}, \mathrm{O}_{3}}+\sigma$. Without aerosols the base $\mathrm{O}_{3}$ is 292.0 DU (high chlorine case). With high aerosols the base $\mathrm{O}_{3}$ is $290.6 \mathrm{DU}$. Thus the $6 \%$ decrease in $\mathrm{O}_{3}$ from the reaction rate change is 13 times greater than the decrease of $0.46 \%$ that results when the aerosols are added to the model.

It is tempting to assume that the large changes in base $\mathrm{O}_{3}$ that occur when the reaction rate is changed imply that the model response to an HSCT perturbation will be very different when the reaction rate is changed. However, this is not the case. Changes in the model's response to a perturbation are determined 



Figure 12. (a) Change in globally and annually averaged column ozone $\left(\triangle G \mathrm{O}_{3}^{\mathrm{HSCT}}\right)$ with emission index, at three different values of the reaction $\mathrm{HO}_{2}+\mathrm{O}_{3} \rightarrow$ $\mathrm{OH}+2 \mathrm{O}_{2}$ The " $-\sigma$ " and " $+\sigma$ " cases are the values of the reaction rate at the lower and upper uncertainty limits, as given by DeMore et al. [1992]. The "nominal" case is the best estimate of this reaction rate, as given by DeMore et al. [1992]. The fleet is located at the low-latitude, high-altitude position $\left(0^{\circ}, 38.5 \mathrm{mbar}\right)$. (b) Same as Figure 12a, for a middle-latitude, middlealtitude fleet location $\left(30^{\circ} \mathrm{N}, 68 \mathrm{mbar}\right)$. (c) Same as Figure 12a, for the high-latitude, low-altitude fleet location $\left(60^{\circ} \mathrm{N}, 120 \mathrm{mbar}\right)$.
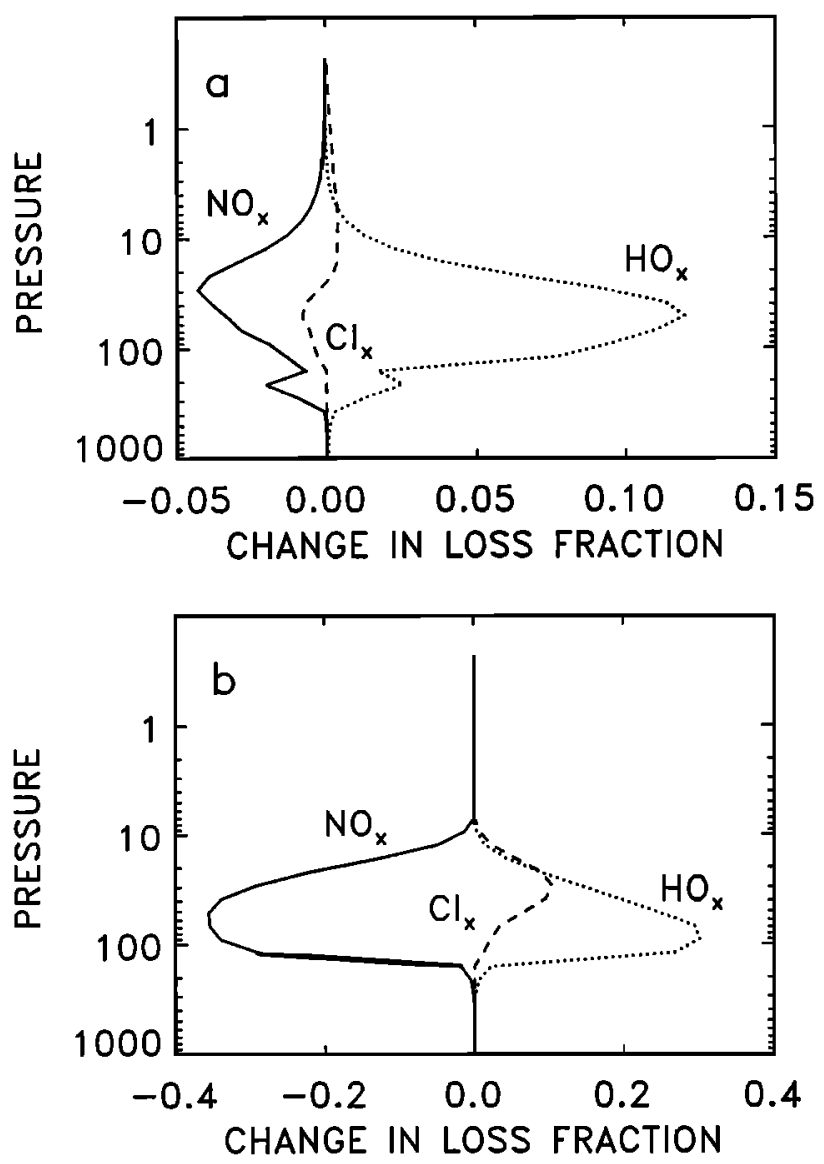

Figure 13. (a) Change in the fraction of total loss of $\mathrm{O}_{3}$ due to the $\mathrm{NO}_{x}, \mathrm{HO}_{x}$, and $\mathrm{Cl}_{x}$ catalytic cycles when the reaction rate for $\mathrm{HO}_{2}+\mathrm{O}_{3} \rightarrow \mathrm{OH}+2 \mathrm{O}_{2}$ is varied from $k-\sigma$ to $k+\sigma$, where $\sigma$ is the uncertainty for the reaction rate given by DeMore et al. [1992]. The plot is for March conditions at $55^{\circ} \mathrm{N}$. (b) Same as Figure 13a, for the case where the background aerosol condition is changed from no aerosols to the high aerosol case.

by changes in the relative contributions of each of the catalytic $\mathrm{O}_{3}$ loss cycles to total $\mathrm{O}_{3}$ loss. Figure 13a shows the changes in the fraction of total loss for the $\mathrm{NO}_{x}, \mathrm{HO}_{x}$, and $\mathrm{Cl}_{x}$ cycles that occur for a change from $k_{\mathrm{HO}_{2}, \mathrm{O}_{3}}-\sigma$ to $k_{\mathrm{HO}_{2}, \mathrm{O}_{3}}+\sigma$ in March at $55^{\circ} \mathrm{N}$. The maximum increase in the rate of $\mathrm{HO}_{x}$-catalyzed loss is about 0.12 of the total loss at about 60 mbar. The maximum reduction in $\mathrm{NO}_{x}$ is less than 0.05 , and peaks at about 30 mbar. Figure 13b shows the changes in fraction of total loss that occur when aerosols are added to the model. Here, the change in $\mathrm{NO}_{x}$ loss fraction is much more dramatic, with a peak reduction of almost 0.4 of the total loss. As has been noticed before [Weisenstein et al., 1993], the $\mathrm{HO}_{x}$ and $\mathrm{Cl}_{x}$ loss cycles play a dominant role in the high aerosol case. Compared to the changes that occur when aerosols are increased, the changes in the roles of the catalytic loss cycles induced by the increased reaction of $\mathrm{HO}_{2}$ with $\mathrm{O}_{3}$ are small. Therefore the reaction rate change does not result in a large change in the model's response to an HSCT perturbation. 


\section{Summary and Conclusions}

We have tested the sensitivity of model predictions of HSCT-induced $\mathrm{O}_{3}$ depletion to systematic variations of five parameters and two reaction rates. The parameters are latitude, altitude, and magnitude of the HSCT emissions, background chlorine, and background sulfate aerosol loading. The reactions are $\mathrm{NO}+\mathrm{HO}_{2} \rightarrow$ $\mathrm{NO}_{2}+\mathrm{OH}$ and $\mathrm{HO}_{2}+\mathrm{O}_{3} \rightarrow \mathrm{OH}+2 \mathrm{O}_{2}$. The HSCT emissions location varied over about an $8 \mathrm{~km}$ vertical range and from the equator to $60^{\circ} \mathrm{N}$ latitude. The magnitude of the emissions was varied over almost an order of magnitude. The background chlorine was varied over a range about as large as the decrease expected over the next century due to decreased use of chlorofluorocarbons. Background aerosols were varied from no aerosols to about 4 times background. Finally, the reactions were varied over their high and low uncertainty limits, as given by DeMore et al. [1992].

This study therefore explored the response of model $\mathrm{O}_{3}$ depletion predictions over a wide range of conditions. The changes in model response with changes in the various parameters are largely what is expected. The largest model sensitivity to emissions occurs when the emissions are injected at low latitudes and high altitudes, in a background atmosphere characterized by low chlorine levels and aerosol loading.

Model predictions of $\mathrm{O}_{3}$ depletion are most sensitive to emissions location and the altitude of the emissions in particular. The same emissions which result in nearly a $10 \%$ reduction in global total $\mathrm{O}_{3}$ if they occur at equatorial high latitudes cause an increase in $\mathrm{O}_{3}$ if they occur at high latitudes and low altitudes. The change in $\mathrm{O}_{3}$ depletion is a strong function of altitude. It is a strong function of latitude only at the highest emission altitudes; for low-altitude emissions the change in depletion between a high and low-latitude fleet location is much smaller.

The response of the model to HSCT emissions varies significantly when the background chlorine and aerosol loading is changed. Model response is most sensitive for low chlorine and aerosol conditions. It is possible that such an atmosphere could occur near the end of the 21st century, if volcanic activity is low for a number of years. The low aerosol loading condition used in this study is thought to be close to the background that would exist in the absence of all volcanic activity. It is unlikely that lower values than this would be observed. Thus while the model is most sensitive to HSCT emissions in the no aerosol state, this state is thought to be outside the expected range of atmospheric variability.

The model predictions of $\mathrm{O}_{3}$ depletion are not particularly sensitive to changes in the rates of the reactions $\mathrm{NO}+\mathrm{HO}_{2} \rightarrow \mathrm{NO}_{2}+\mathrm{OH}$ and $\mathrm{HO}_{2}+\mathrm{O}_{3} \rightarrow \mathrm{OH}+2 \mathrm{O}_{2}$ studied over their range of uncertainty. However, when the reaction rate for $\mathrm{HO}_{2}+\mathrm{O}_{3} \rightarrow \mathrm{OH}+2 \mathrm{O}_{2}$ is varied over its uncertainty limits, model global $\mathrm{O}_{3}$ values change by about $19 \mathrm{DU}$. This change is relatively large. For comparison, it is larger than the change in $\mathrm{O}_{3}$ resulting from the variation of background chlorine from
1.4 to $3.7 \mathrm{ppbv}$. A large change in model $\mathrm{O}_{3}$ levels in response to a parameter variation therefore does not indicate either the magnitude of the model response to a perturbation or the uncertainty of a model prediction of atmospheric response to a perturbation. This point needs to be kept in mind when determining how much confidence to place in a specific model prediction.

The chlorine, aerosol, and magnitude of HSCT emissions were all varied over a realistic range. The variation of $\mathrm{O}_{3}$ depletion predictions due to changes in the parameters indicates the uncertainty in the model predictions due to the uncertainty of the input parameters. In contrast, the fleet distribution and its variation in latitude and altitude is designed to test the sensitivity of the model and does not vary over a likely range. Therefore while this study reveals the sensitivities to variations in fleet location, it does not give an indication of the uncertainty in predictions of $\mathrm{O}_{3}$ due to uncertainties in fleet location and spatial distribution. The results should give a good indication of the relative impact of individual flights or flight corridors occurring at different altitudes and latitudes, however. Although this study was not designed to examine lower stratospheric transport processes, the sensitivity to emissions location indirectly suggests that model transport processes may be a source of substantial uncertainty for predictions of $\mathrm{HSCT}$-induced $\mathrm{O}_{3}$ depletion.

Acknowledgments. The authors would like to recognize R. S. Stolarski for many helpful discussions.

\section{References}

Bekki, S., and J. A. Pyle, Potential impact of combined $\mathrm{NO}_{x}$ and $\mathrm{SO}_{\mathrm{x}}$ emissions from future high speed civil transport aircraft on stratospheric aerosols and ozone, Geophys. Res. Lett., 20, 723-726, 1993.

Considine, D. B., A. R. Douglass, and C. H. Jackman, Effects of a polar stratospheric cloud parameterization on ozone depletion due to stratospheric aircraft in a twodimensional model, J. Geophys. Res., 99, 18,879-18,894, 1994.

Davis, D. D., and M. Chin, Contribution of carbonyl sulfide to stratospheric background sulfur aerosol, Eos Trans. $A G U, 74,(16)$, Spring Meeting suppl., 75, 1993.

DeMore, W. B., D. M. Golden, R. F. Hampson, C. J. Howard, C. E. Kolb, M. J. Kurylo, M. J. Molina, A. R. Ravishankara, and S. P. Sander, Chemical kinetics and photochemical data for use in stratospheric modeling, $J P L$ Publ. 92-20, Jet Propul. Lab., Pasadena, Calif., 1992.

Dopplick, T.G., The heat budget, in The General Circulation of the Tropical Atmosphere and Interactions with Extratropical Latitudes, vol. 2, edited by R.E. Newell, J.W. Kidson, D.G. Vincent, and C.J. Boer, pp. 27-94, MIT Press, Cambridge, Mass. 1974.

Dopplick, T.G., Radiative Heating of the Global Atmosphere: Corrigendum, J. Atmos. Sci., 36, 1812-1817, 1979.

Douglass, A. R., C. H. Jackman, and R. S. Stolarski, Comparison of model results transporting the odd nitrogen family with results transporting separate odd nitrogen species, J. Geophys. Res., 94, 9862-9872, 1989.

Douglass, A. R., C. H. Jackman, R. B. Rood, A. C. Aikin, R. 
S. Stolarski, M. P. McCormick, and D. W. Fahey, Natural cycles, gases, in Atmospheric Effects of Stratospheric Aircraft: A First Program Report, NASA Ref. Publ. 1272, 1992.

Douglass, A. R., R. B. Rood, C. J. Weaver, M. C. Cerniglia, and $K$. F. Brueske, Implications of three-dimensional tracer studies for two-dimensional assessments of the impact of supersonic aircraft on stratospheric ozone, J. Geophys. Res., 98, 8949-8963, 1993.

Graedel, T. E., D. Cariolle, M. A. Geller, J. L. Kerrebrock, D. H. Lister, K. Mauersberger, S. A. Penkett, U. Schmidt, S. E. Schwartz, and S. Solomon, Atmospheric Effects of Stratospheric Aircraft: An Evaluation of NASA's Interim Assessment, National Academy Press, Washington, D. C., 1994.

Hanson, D. and A. R. Ravishankara, The reaction probabilities of $\mathrm{ClONO}_{2}$ and $\mathrm{N}_{2} \mathrm{O}_{5}$ on 40 to $75 \%$ sulfuric acid solutions, J. Geophys. Res., 96, 17,307-17,314, 1991.

Hofmann, D.J., and S. Solomon, Ozone destruction through heterogeneous chemistry following the eruption of El Chichon, J. Geophys. Res., 94, 5029-5041, 1989.

Jackman, C.H., et al., Two-dimensional intercomparison of stratospheric models, NASA CP-3042, 608 pp., NASA Code NTT-4, 1989.

Jackman, C. H., A. R. Douglass, R. B. Rood, R. D. McPeters, and P. E. Meade, Effect of solar proton events on the middle atmosphere during the past two solar cycles as computed using a two-dimensional model, J. Geophys. Res., 95, 7414-7428, 1990.

Jackman, C.H., A.R. Douglass, K.F. Brueske, and S.A. Klein, The influence of dynamics on two-dimensional model results: Simulations of ${ }^{14} \mathrm{C}$ and stratospheric aircraft $\mathrm{NO}_{x}$ injections, J. Geophys. Res., 96, 22559-22572, 1991.

Johnston, H., Reduction of stratospheric ozone by nitrogen oxide catalysts from supersonic transport exhaust, $S c$ ience, 173, 517-522, 1971.

Johnston, H. S., D. E. Kinnison, and D. J. Wuebbles, Nitrogen oxides From high-altitude aircraft: An update of potential effects on ozone, J. Geophys. Res., 94, 16351$16363,1989$.

Ko, M., Ozone response to aircraft emissions: sensitivity studies with two-dimensional models, in Atmospheric Effects of Stratospheric Aircraft: A First Program Report, NASA Ref. Publ. 1272, 1992.

Ko, M., and A. R. Douglass, Update of model simulations for the effects of stratospheric aircraft, in Atmospheric Effects of Stratospheric Aircraft: A Third Program Report, NASA Reference Publication 1313, 1993.

Ko, M., and D. Weisenstein, Ozone response to aircraft emissions: Sensitivity to heterogeneous reactions, in
Atmospheric Effects of Stratospheric Aircraft: A Second Program Report, NASA Reference Publication 1293, 1993.

Miake-Lye, R. C., Designing a methodology for future air travel scenarios, in Atmospheric Effects of Stratospheric Aircraft: A First Program Report, NASA Ref. Publ. 1272, 1992.

Pitari, G., V. Rizi, L. Ricciardulli, and G. Visconti, Highspeed civil transport impact: Role of sulfate, nitric acid trihydrate, and ice aerosols studied with a twodimensional model including aerosol physics, J. Geophys. Res., 98, 23,141-23,164, 1993.

Prather, M. J., and E. Remsberg, The Atmospheric Effects of Stratospheric Aircraft: Report of the 1992 Models and Measurements Workshop, NASA Ref Publ. 1292, 1993.

Rosenfield, J. E., M. R. Schoeberl, and M. A. Geller, A Computation of the stratospheric diabatic residual circulation using an accurate radiative transfer model, J. Atmos. Sci., 44, 859-876, 1987.

Steele, H. M., and P. Hamill, Effects of temperature and humidity on the growth and optical properties of sulfuric acid-water droplets in the stratosphere, J. Aerosol Sci., 12, 517-528, 1981.

Tie, X. X., G. Brasseur, X. Lin, P. Friedlingstein, C. Granier, and P. Rasch, The Impact of High Altitude Aircraft on the Ozone Layer in the Stratosphere, J. Atmos. Chem., 18, 103-128, 1994.

Toon, O. B., R. P. Turco, P. Hamill, C. S. Kiang, and R. C. Whitten, A one-dimensional model describing aerosol formation and evolution in the stratosphere, II, sensitivity studies and comparison with observations, J. Atmos. Sci., 36, 718-736, 1979.

Weisenstein, D. K., M. K. W. Ko, J. M. Rodrigurez, and N. D. Sze, Impact of heterogeneous chemistry on modelcalculated ozone change due to high speed civil transport aircraft, Geophys. Res. Lett., 18, 1991-1994, 1991.

Weisenstein, D. K., M. K. W. Ko, J. M. Rodrigurez, and N. D. Sze, Effects on stratospheric ozone from high-speed civil transport: Sensitivity to stratospheric aerosol loading, J. Geophys. Res., 98, 23133-23140, 1993.

World Meteorological Organization (WMO), Scientific assessment of stratospheric ozone: 1991, Global Ozone Res. and Monit. Proj., WMO Rep. 25, 1992.

D. B. Considine, A. R. Douglass, and C. H. Jackman, Code 916, NASA Goddard Space Flight Center, Greenbelt, MD 20771.

(Received April 28, 1994; revised September 12, 1994; accepted October 13, 1994.) 